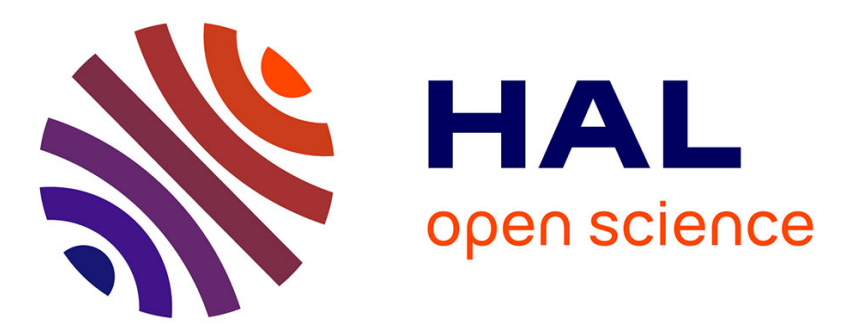

\title{
Hybrid fuzzy-PID control of a nuclear Cyber-Physical System working under varying environmental conditions
}

Wei Wang, Francesco Di Maio, Enrico Zio

\section{To cite this version:}

Wei Wang, Francesco Di Maio, Enrico Zio. Hybrid fuzzy-PID control of a nuclear Cyber-Physical System working under varying environmental conditions. Nuclear Engineering and Design, 2018, 331, pp.54 - 67. 10.1016/j.nucengdes.2018.02.035 . hal-01786586

\section{HAL Id: hal-01786586 \\ https://hal-centralesupelec.archives-ouvertes.fr/hal-01786586}

Submitted on 19 Mar 2020

HAL is a multi-disciplinary open access archive for the deposit and dissemination of scientific research documents, whether they are published or not. The documents may come from teaching and research institutions in France or abroad, or from public or private research centers.
L'archive ouverte pluridisciplinaire HAL, est destinée au dépôt et à la diffusion de documents scientifiques de niveau recherche, publiés ou non, émanant des établissements d'enseignement et de recherche français ou étrangers, des laboratoires publics ou privés. 


\title{
Hybrid Fuzzy-PID Control of a Nuclear Cyber-Physical System Working Under Varying Environmental Conditions
}

\author{
Wei Wang ${ }^{1}$, Francesco Di Maio ${ }^{1}$, Enrico Zio ${ }^{1,2}$ \\ ${ }^{1}$ Energy Department, Politecnico di Milano, Via La Masa 34, 20156 Milano, Italy \\ ${ }^{2}$ Chair on System Science and the Energy Challenge, Fondation Electricite' de France (EDF), \\ CentraleSupélec, Université Paris Saclay, 91190 Gif-sur-Yvette, France
}

\begin{abstract}
In real-time control of Cyber-Physical Systems (CPSs), physical process variables are monitored and processed by intelligent controllers for keeping the values of safety parameters between given thresholds. Environmental conditions can affect the system dynamics and also the controller function. This paper presents a hybrid fuzzyPID (Proportional-Integral-Derivative) controller, which learns the optimal PID controller parameters and adapts them according to the environmental parameters and process variables values.

The proposed intelligent controller is applied to respond to the changes and transients in the environmental inlet air temperature of the secondary loop of a LeadBismuth Eutectic eXperimental Accelerator Driven System (LBE-XADS), for keeping the secondary average coolant temperature in a range of values between two safety thresholds.

Keywords: Cyber-Physical System; Hybrid Fuzzy-PID Controller; Environmental Conditions; Nuclear Power Plants (NPPs); Lead-Bismuth Eutectic eXperimental Accelerator Driven System (LBE-XADS).
\end{abstract}




\section{ABBREVIATIONS}

$\begin{array}{ll}\text { CPS } & \text { Cyber-Physical System } \\ \text { NPP } & \text { Nuclear Power Plant } \\ \text { PID } & \text { Proportional-Integral-Derivative } \\ \text { LBE-XADS } & \text { Lead-Bismuth Eutectic eXperimental Accelerator Driven } \\ & \text { System } \\ \text { FLC } & \text { Fuzzy Logic Control }\end{array}$

\section{NOTATIONS}

$t$

$e(t)$

$K_{p}$

$K_{i}$

$K_{d}$

$P(t)$

$Q(t)$

$T_{L B}^{C, P}$

$T_{L B}^{P, C}$

$T_{L B}^{a c, C}$

$T_{o}^{i n, S}$

$T_{o}^{\text {out }, S}$

$T_{o}^{a v, S}$

$\Gamma_{a}(t)$

$T_{o}^{\text {th }, u}$

$T_{o}^{\text {th }, l}$

$\Psi$

$T_{a}^{i n, S}$

$T_{o}^{r e f, S}$

$d K_{p}$

$d K_{i}$

$d K_{d}$

$x$

$y$

$f$

$\bar{e}_{S S}$

$A_{S P}$

$T_{j}$

$I_{j}$

$R_{j}$

$Y$

$\mu_{Y}$
Time

Residual between the measured value and the set point

Proportional gain

Integral gain

Derivative gain

LBE-XADS thermal power

Proton energy

Primary outlet coolant temperature

Primary inlet coolant temperature

Average in-core temperature

Secondary inlet oil temperature

Secondary outlet oil temperature

Secondary average oil temperature

Air mass flow rate

Upper threshold of the oil temperature

Lower threshold of the oil temperature

Monotonically increasing function

Inlet air temperature

Set point of secondary average oil temperature

Change of the proportional gain

Change of the integral gain

Change of the derivative gain

Input of an input-output data pair

Output of an input-output data pair

Mapping function

Average steady-state drift

Settling area

Fuzzy sets of the $j$-th Antecedent, $j=1,2, \ldots, 7$

Fuzzy sets of the $j$-th Consequent

$j$-th fuzzy rule

Fuzzy set obtained from a fuzzy conclusion

Membership function 


\section{INTRODUCTION}

A Cyber-Physical System (CPS) combines a cyber system with a physical system, integrating computational resources into physical processes in order to add new capabilities to the original stand-alone physical system and realize real-time monitoring, dynamic control and decision support. The benefit from such capabilities makes CPSs increasingly operated in transportation, energy, medical and health-care, and other applications [1]-[3]. In CPSs, the cyber computation and the physical processes are dependable, and interact with each other through multiple and distinct modes (e.g., embedded cyber controllers monitor and control the system physical variables, whilst physical processes affect, at the same time, the monitoring system and the computation units by wired or wireless networks [2], [4], [5]). This information can be intelligently manipulated to guarantee the system to be self-adaptive, robust and reliable with respect to components failures and changes of the environmental operational conditions [4], [68], [16]. For example, in [44] the flight control of parafoil systems is shown to be improved when wind conditions are duly taken into account, whereas in $[45,46]$ adaptive speed control strategies of autonomous vehicles under various traffic conditions are proposed.

Adaptivity of CPS control rules can be achieved based on real-time monitoring of physical and environmental variables. Stability is the main concern for real-time monitoring of CPSs. To satisfactorily control the dynamical systems, it is basically required the changes in the observed behavior of the physical system in case of any small perturbations imposed by the controller to be kept at minimum [37].

Traditionally, Proportional-Integral-Derivative (PID) control systems have been used for retroacting to actuators the actions to be undertaken for real-time controlling the system (see Fig. 1) [8], [16], [40]. Digital PIDs have overcome analog PIDs [9] but still cannot intelligently adapt their parameters setting to changing environmental conditions: a predesigned control function is implemented by a command signal, to control the physical process variables, which, once measured, are compared with a set point that originates the residual $e(t)$ (see Fig. 1). A strong limitation of this traditional 
control approach is that incorrect calibration of the PID parameters with respect to the current physical and environmental conditions may significantly degrade the control performance and robustness [9], [10]. Moreover, under this control scheme, the physical system may be led to dangerous operational conditions not only due to unforeseen changes of the environmental conditions but also due to human errors, malicious attacks through the network and poor/wrong database use in support to parameters setting (see Fig. 2).

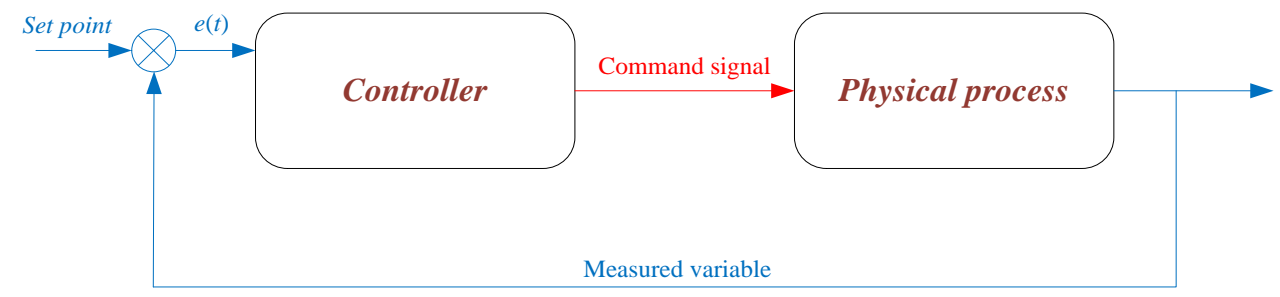

Fig. 1. The PID control scheme

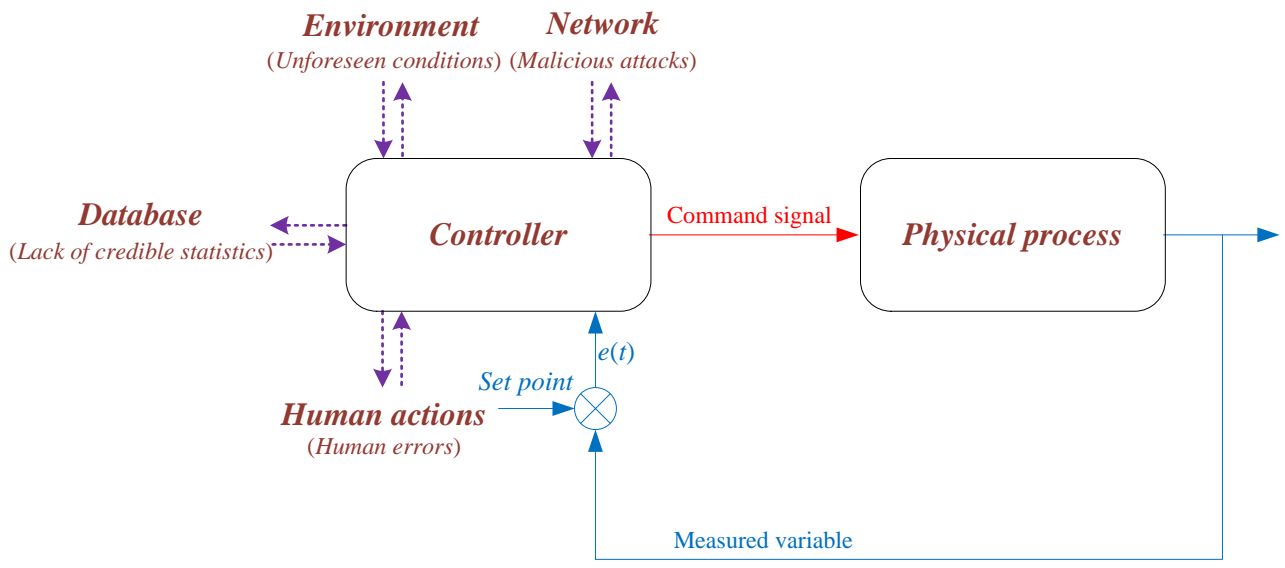

Fig.2. The cyber control scheme

To overcome the challenges of conventional PID control and add learning capabilities to a CPS controller, a Fuzzy Logic Control (FLC) strategy can be of help [14]. FLC has been increasingly used in real-world control engineering [15], [17], [39], [41], [47]. The fuzzy rules are obtained by a fuzzification of the ranges of the measured physical variables (Antecedents) and the logic mapping into the ranges of the control parameters (Consequents) [18], [19]. Nonlinear analysis has been adopted to build the FLC rules and improve the control performance, especially for systems operating under uncertain physical and environmental conditions [20]-[23]. In most cases, the fuzzy 
rules are based on expert experience and knowledge of the system processes [24], [25]. The integration of a PID with a FLC (e.g., fuzzy-PID) is proven to be an intelligent, nonlinear and robust strategy that improves the performance of conventional PIDs, by readjusting the PID gains in an on-line and real-time manner [23], [42]. The resulting fuzzy-PID controller is, thus, aimed at accounting for time-dependent interactions of the cyber world with the physical world in an intelligent feedback loop, while at the same time, guaranteeing the stability of the CPSs, without causing the loss of control of the physical behaviors.

In practice, environmental conditions can play an important role on the physical process by triggering unforeseen system dynamics. For example, seawater is often used as the coolant of the secondary coolant circuit of Nuclear Power Plants (NPPs) and any seawater temperature change may affect the NPP cooling capability and, eventually, its performance and safety [11]; in Heating, Ventilation and Air-Conditioning (HVAC) systems, changes of the environmental temperature make the heat transfer coefficient and the energy balances change [8], [12], [13]. Thus, environmental parameters should be measured and integrated into the cyber real-time monitoring and control in an intelligent manner: the resulting CPS is expected to learn the optimal control settings in different environmental conditions, and self-adapt to the varying conditions to preserve safe operation of the physical system and avoid loss of control.

In this work, environmental parameters values are used as inputs of a fuzzy-PID controller that optimally sets the PID gains, denoted as $K_{p}, K_{i}$ and $K_{d}$, for the proportional, integral, derivative parts of the control, respectively. By so doing, the hybrid fuzzy-PID is capable of controlling the CPS under varying environmental conditions. To increase the transparency of the hybrid fuzzy-PID control, the fuzzy rules are here optimized by resorting to a grid-type fuzzy partitioning approach [24], [26][29], where the fuzzy sets and the fuzzy rules are learnt from examples of input variables and optimal control settings.

The proposed controller is applied to respond to changes and transients of the environmental inlet air temperature of the secondary loop of a Lead-Bismuth Eutectic 
eXperimental Accelerator Driven System (LBE-XADS) [30], so as to maintain the secondary average coolant temperature at a desired reference value, in-between two safety thresholds. The optimized CPS is finally compared with a traditional PID control scheme with fixed parameters and with a linearly variable gain PID control scheme.

The remainder of the paper is organized as follows. Section II presents in details the LBE-XADS that is taken as CPS case study. In Section III, an overview of the proposed hybrid fuzzy-PID control strategy is presented for the temperature control of the secondary cooling system of the LBE-XADS, under varying environmental conditions. The results of the proposed approach are compared with the results of the reference PID control in Section IV. Section V draws the conclusions of the work.

\section{CPS CASE STUDY: THE LBE-XADS}

\section{A. The Physical Process}

The Lead-Bismuth Eutectic eXperimental Accelerator Driven System (LBE$\mathrm{XADS}$ ) is a sub-critical, fast reactor in which the fission process for providing thermal power $P(t)$ is sustained by an external neutron source through spallation reaction by a proton beam $Q(t)$ accelerated by a synchrotron on a Lead-Bismuth Eutectic (LBE) target.

The primary cooling system is of pool-type with LBE liquid metal coolant leaving the top of the core, at full power nominal conditions, at temperature $\tau_{L B}^{C, P}$ equal to $400^{\circ} \mathrm{C}$ pushed by natural circulation enhanced by argon gas injection into the heat exchangers of the secondary cooling circuit and then re-entering the core from the bottom through the down-comer at temperature $\tau_{L B}^{P, C}$ equal to $300^{\circ} \mathrm{C}$. The average in-core temperature of the LBE $T_{L B}^{a c, C}$ is taken as the mean of $\tau_{L B}^{C, P}$ and $\tau_{L B}^{P, C}$.

In the secondary cooling system, a flow of an organic diathermic oil is cooled in a secondary heat exchanger, from the inlet temperature $T_{o}^{i n, S}$ equal to $320^{\circ} \mathrm{C}$ to the outlet temperatures $T_{o}^{o u t, S}$ equal to $280^{\circ} \mathrm{C}$, at full nominal power of $80 \mathrm{MWth}$. Thus, the average nominal temperature $T_{o}^{a v, S}$ is $300^{\circ} \mathrm{C}$. Cooling of the diathermic oil is obtained 
through an air flow $\Gamma_{a}(t)$ (nominally equal to $750 \mathrm{~kg} / \mathrm{s}$ [43]) provided by three air coolers connected in series (i.e., secondary heat exchanger), that can provide a maximum air flow rate of $1000 \mathrm{~kg} / \mathrm{s}[30,43]$.

\section{B. The Control Strategy}

In [30], the LBE-XADS was originally equipped with a simultaneous feedforwardfeedback control (whose scheme is shown in Fig. 3) to control the system physical dynamics by maintaining $T_{o}^{a v, S}$ close to $300^{\circ} \mathrm{C}$ during any operational transient and any design basis accident, for any LBE-XADS prototypical plant operated in any location in the World, where the air temperature ranges in $[0,30]^{\circ} \mathrm{C}$ with an average value equal to $20^{\circ} \mathrm{C}[30]$. On the contrary, an oil temperature beyond the upper threshold $T_{o}^{t h, u}$ equal to $340^{\circ} \mathrm{C}$ would lead to degradation of its physical and chemical properties (i.e., hightemperature failure mode), whereas a temperature below the lower threshold $T_{o}^{t h, l}$ equal to $280^{\circ} \mathrm{C}$ could result in thermal shocks for the primary fluid and, eventually, for the structural components (i.e., low-temperature failure mode) [30], [31]. The average temperature of diathermic oil $T_{o}^{a v, S}$ is the controlled variable, and the air mass flow rate $\Gamma_{a}(t)$ is the command signal provided by the controller. As shown in Fig. 3, the feedback controller was a conventional PID with low values of the proportional $\left(K_{p}\right)$, the integral $\left(K_{i}\right)$ and the derivative $\left(K_{d}\right)$ gains, and contributing for $70 \%$ of the control strategy; the remaining 30\% was provided by the feedforward action obtained by a monotonically increasing function $\Psi$ relating the required air mass flow rate $\Gamma_{a}(t)$ to the reactor power $P(t)$, according to Eq. (1):

$$
\Gamma_{a}(t)=K_{p} e(t)+K_{i} \int e(t) d t+K_{d} \frac{d e(t)}{d t}+\Psi(P(t))
$$

The three feedback terms of Eq. (1) are:

1) The Proportional $(P)$-term, that accounts for a control action proportional to the residual $e(t)$ (i.e., the difference between the desired set point $T_{o}^{r e f, S}$ and the value of $T_{o}^{a v, S}$ measured at time $t$ ) and that may lead to the large values of the steady-state residual over time in case of inaccurate setting; 
2) The Integral $(I)$-term, that accumulates the past values of the residual over time, to reduce the steady-state residuals;

3) The Derivative $(D)$-term, that sets the control action based on the present slope of the residual curve over time, to improve the response to a dynamic transient.

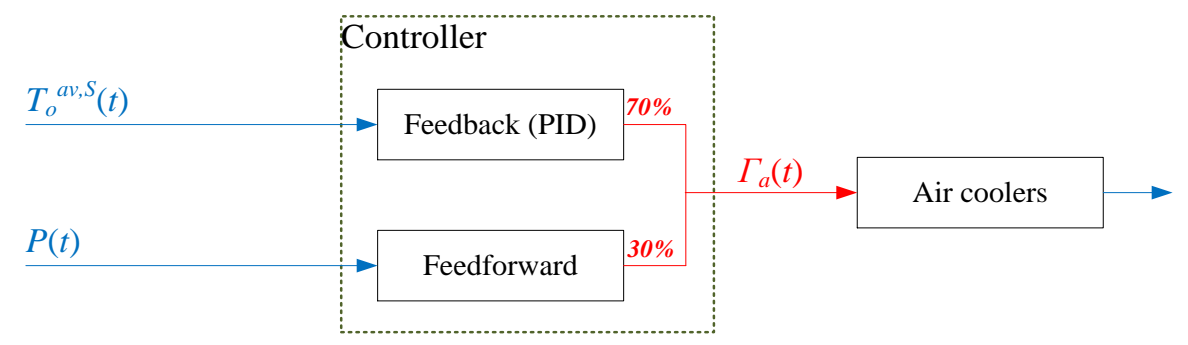

Fig. 3. Structure of the LBE-XADS control strategy

Fig. 4 shows the overall scheme of the LBE-XADS digital acquisition chain of environmental temperature $T_{a}^{i n, S}$ and diathermic oil temperature $T_{o}^{a v, S}$, that acts as the bounding layer between the physical process and the computation layer of the feedback controller. This digital acquisition chain is composed of two redundant channels (A and B) (see Fig. 4 shadowed box). Each channel consists of one signal sensor (S-A and S$\mathrm{B}$, measuring the average oil temperature $T_{o}^{a v, S}$ ), one Bistable Processor Logic (BPL) subsystem (BPL-A and BPL-B), and one Local Coincidence Logic (LCL) subsystem (LCL-A and LCL-B). An independent signal sensor and an independent BPL is installed in each channel. Two redundant measured signals of $T_{o}^{a v, S}$ are collected by S-A and S$\mathrm{B}$ and processed by the corresponding BPL. The signal processing proceeds only if both channels produce the residual $e(t)$ compared with the set point $T_{o}^{r e f, S}$ : each $e(t)$ from a BPL is sent to both LCL-A and LCL-B, which process information by an "AND" gate. In other words, the residual signal is processed only when receiving two residual signals $e(t)$ originating from the two different BPLs; the information is, then, processed by an "OR" gate at the end of the digital acquisition chain. Once the residual signal $e(t)$ is processed, it is sent to the PID feedback. 


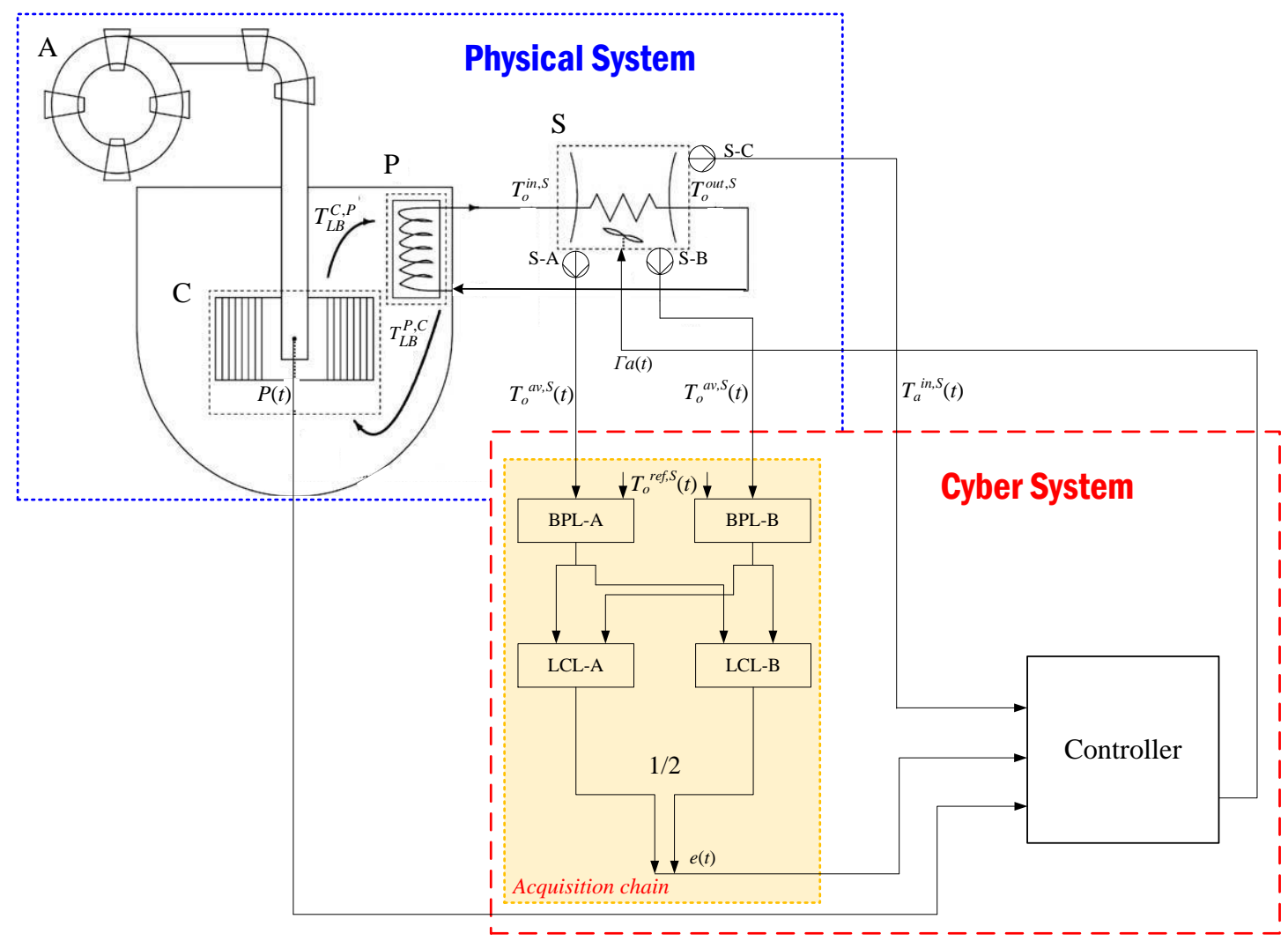

Fig. 4. The simplified scheme of the LBE-XADS with its digital acquisition chain

\section{CONTROL STRATEGY UNDER VARYING ENVIRONMENTAL CONDITIONS}

\section{A. System Properties Identification}

To show the effect of the environmental variable $T_{a}^{i n, S}$ on the system dynamics and the corresponding control performance of the original PID, a Matlab/Simulink model of the LBE-XADS has been run $N_{l}=50$ times with a mission time $t_{M}$ of $3000 \mathrm{~s}$. The inlet air temperature $T_{a}^{i n, S}$, initially equal to $20^{\circ} \mathrm{C}$, changes at time $t=1000$ s to a random value $T_{a, C}^{i n, S}$ sampled from a uniform distribution $\mathrm{U} \sim[0,30]^{\circ} \mathrm{C}$. The results are shown in Fig. 5 (solid lines): at time $t=1000 \mathrm{~s}$, the physical process rapidly responds to the change of the environmental condition (i.e., the inlet air temperature) and the average oil temperature $T_{o}^{a v, S}$ deviates from its reference level $\left(300^{\circ} \mathrm{C}\right)$ towards a new stationary temperature after approximately 800 s, confirming the adaptive capability of the original PID.

For completeness, some (uncontrollable) scenarios (dashed lines) are also shown 
where $T_{o}^{a v, S}$ continues rising, eventually reaching the threshold of the high-temperature failure mode before the end of the mission time, because triggered by temperature changes that fall out of the design limits of the cooling system (e.g., for $T_{o}^{a v, S}>300^{\circ} \mathrm{C}$ the maximum $\Gamma_{a}(t)$ equal to $1000 \mathrm{~kg} / \mathrm{s}$ is not capable of removing the decay heat). In light of this design limit of the LBE-XADS cooling system, in what follow we will discard such uncontrollable scenarios and focus on improving the controllability of the LBE-XADS under the nominal temperature range $[0,30]^{\circ} \mathrm{C}$.

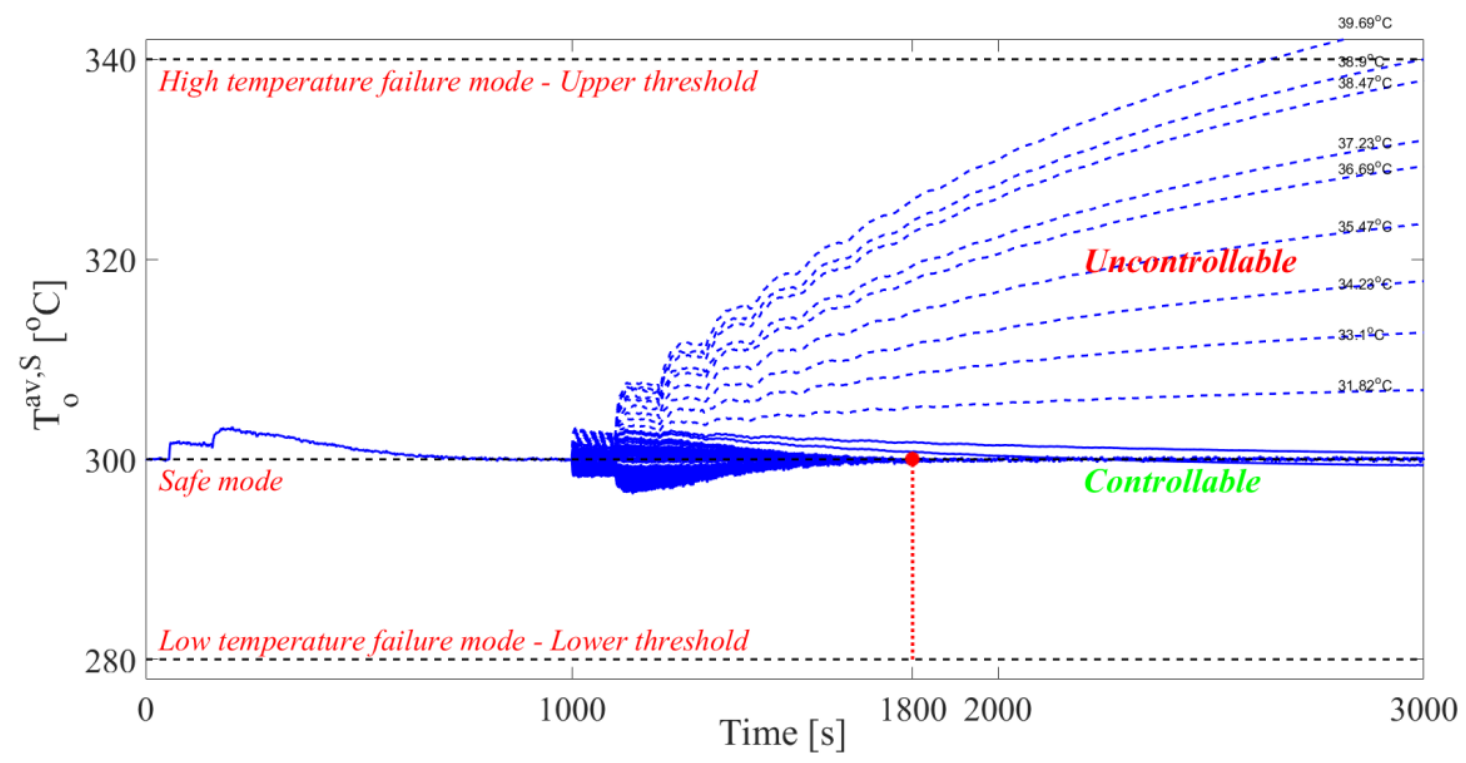

Fig. 5. The $N_{1}=50$ runs of the LBE-XADS controlled with the original PID when the inlet air temperature changes to a random value uniformly distributed in $[0,30]^{\circ} \mathrm{C}$ at time $t=1000 \mathrm{~s}$

\section{B. The Hybrid Fuzzy-PID Controller}

A hybrid fuzzy-PID controller that automatically adapts the PID gains to different inlet air temperature $T_{a}^{i n, S}(t)$ is here proposed. The structure of the controller is shown in Fig. 6. The idea is that the Fuzzy logic element "filters" the $T_{a}^{i n, S}$ (Antecedent) and, based on the fuzzy logic reasoning, it provides the PID with the adaptation gain changes, $d K_{p}, d K_{i}$ and $d K_{d}$ (Consequents), that need to be added to the current values of the gains $K_{p}, K_{i}$ and $K_{d}$ of Eq. (1), in order to adapt to the changed environmental conditions.

The rules of the FLC are learnt by resorting to a grid-type fuzzy partitioning approach, as illustrated in the next subsection [24], [26]-[29], [32]. 


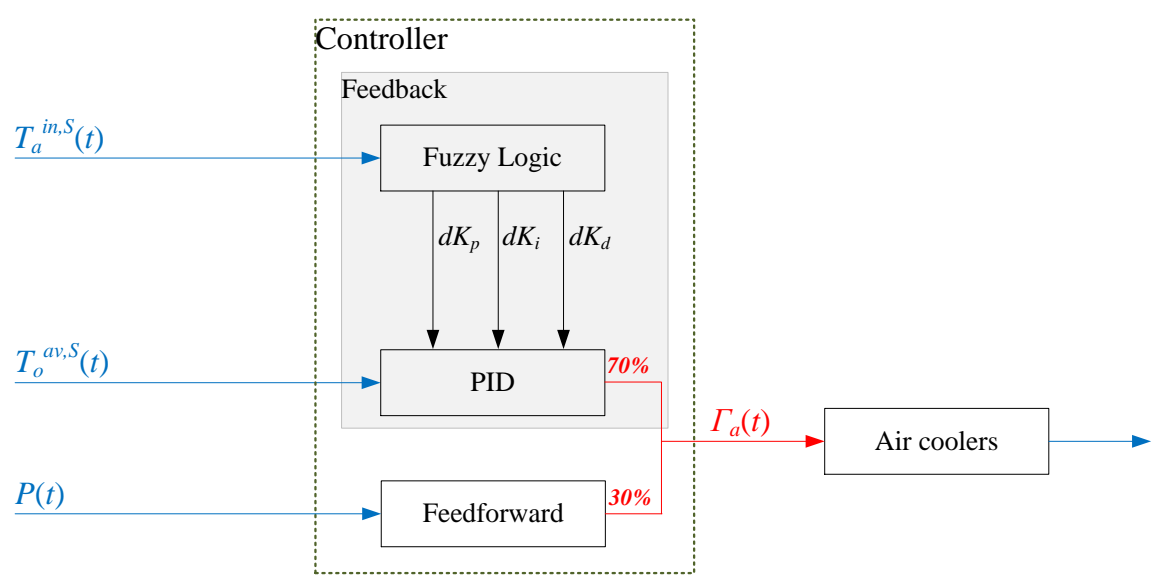

Fig. 6. Structure of the controller under variable inlet air temperature conditions

\section{a. The Learning Algorithm}

Fuzzy logic is used for combining a number of antecedents and consequents linguistic statements into relations by fuzzy connections, where a general grid-type fuzzy partitioning approach can be used to learn the fuzzy rules from the numerical data of the sampled input-output data pairs [26], [29], [32]. The objective of the grid-type fuzzy partitioning approach is to separate the input-output feature space into a set of uniform or non-uniform grids with predefined membership functions, and, then, to obtain the most transparent fuzzy rules linking the antecedents and consequents of the available examples. The key point of the approach is that the optimal input-output data pairs are those that can be univocally mapped in the feature space, which means that the visual connection between antecedents and consequents should be explicit. Taking a one-input-one-output FLC as illustrative example, suppose $n$ optimal input-output data pairs are obtained from $m$ pairs of examples:

$$
\left(x^{(1)}, y^{(1)}\right),\left(x^{(2)}, y^{(2)}\right), \cdots,\left(x^{(n)}, y^{(n)}\right)
$$

where $x$ and $y$ are the input and the output, respectively. The $n(x, y)$ data pairs can be plotted in their feature space. If the data pairs show a clear mapping function $f: x \rightarrow y$ (see Fig. 7(a)), decision makers can determine a set of fuzzy rules with predefined membership functions, according to their knowledge, whereas when the data pairs scatter in the feature space (see Fig. 7(b)), and the connection between $x$ and $y$ is implicit, the fuzzy sets and fuzzy rules cannot be univocally generated. 


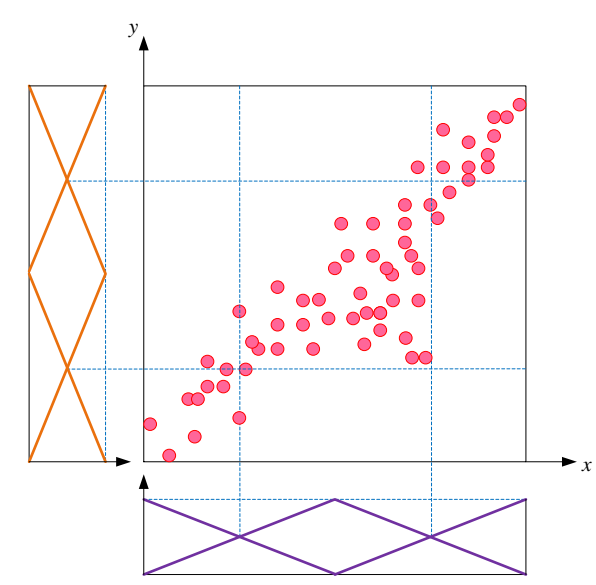

(a)

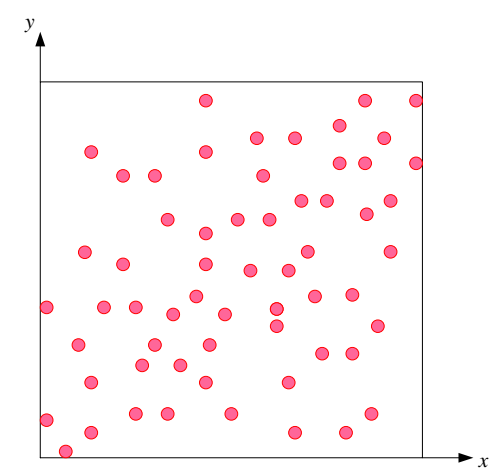

(b)

Fig. 7. Illustration of the general grid-type fuzzy partitioning approach: (a) optimal input-output data pairs, presenting a clear relationship in the feature space, to generate univocal fuzzy sets and fuzzy rules; (b) data pairs scattered in the feature space.

\section{b. Fuzzy Rules Generation for the Hybrid Fuzzy-PID Controller}

The generation of the fuzzy sets and rules from examples of input variables and optimal control settings follows two steps as for the grid-type fuzzy partitioning approach. Step 1 collects the optimal input-output data pairs from the randomly sampled examples and extracts the optimal pairs among the collected examples on the basis of two performance indexes. Step 2 generates the fuzzy sets and the fuzzy rules for the learnt significant input-output data pairs.

\section{Step 1: Collection of the input-output data pairs.}

We define two performance indexes to be used for extracting the optimal pairs with respect to one trial of the simulation of the LBE-XADS (controlled with the original PID) in which the inlet air temperature $T_{a}^{i n, S}$ changes to a random value uniformly distributed in $[0,30]^{\circ} \mathrm{C}$, at $t=1000 \mathrm{~s}$. The profile of the average oil temperature $T_{o}^{a v, S}$ within the mission time of $3000 \mathrm{~s}$ is shown in Fig. 8 . When $T_{a}^{i n, S}$ changes to a random value $T_{a, C}^{i n, S}$ at $t=1000 \mathrm{~s}$, the physical process rapidly responds to the change of environmental condition. $T_{o}^{a v, S}$ recovers from the step response after a resettling time roughly equal to 800 s, and the system dynamics reaches a new steady state. 


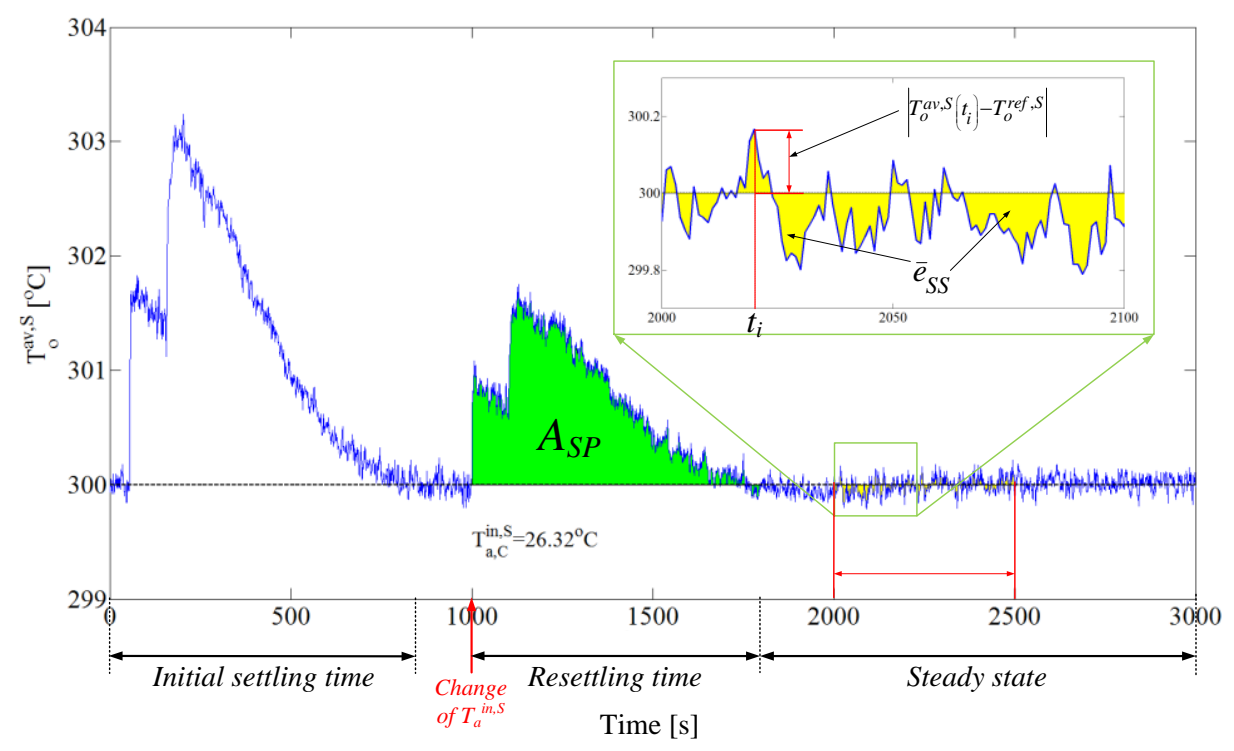

Fig. 8. Illustration of the characterization indexes

As it is known, in the PID controller, the steady-state residual error is inversely proportional to $K_{p}$, whose inappropriate value renders the control unstable, whereas $K_{d}$ limits the high-frequency noise at the system steady state. Thus, the performances of $K_{p}$ and $K_{d}$ are to be evaluated by an average steady-state drift $\left(\bar{e}_{S S}\right)$ defined in Eq. (3) below, that is the average residual of $T_{o}^{a v, S}$ with respect to $T_{o}^{r e f, S}$ after the system reaches a new steady-state condition. To obtain the optimal $\left(T_{a, C}^{i n, S}, d K_{p}\right)$ and $\left(T_{a, C}^{i n, S}, d K_{d}\right)$ data pairs to be used for the learning algorithm of Section III.B.a, $\bar{e}_{S S}$ has to be minimized:

$$
\bar{e}_{S S}=\frac{\sum_{i=1}^{P}\left|T_{o}^{a v, S}\left(t_{i}\right)-T_{o}^{r e f, S}\right|}{P}
$$

where, the time interval $\left[t_{1}, t_{P}\right]$ is the period of time after $T_{o}^{a v, S}$ reaches steady state and, $P$ is the number of the temperature measurements within the period. In this study, $\left[t_{1}, t_{P}\right]$ is taken equal to $[2000,2500] \mathrm{s}$ and, thus, $P=501$. Notice that $\bar{e}_{S S}=0.10^{\circ} \mathrm{C}$ is taken as the largest acceptable value of the average steady-state bias, taking into account the value of $0.07^{\circ} \mathrm{C}$ of the original model at full power, nominal condition and the uncertainty in the sampling. On the other side, it is also known that $K_{i}$ drives the PID adjustment towards the steady state by accumulating the past values of the residual over time to reduce the steady-state residuals. Thus, the better tuned is the $K_{i}$ value the better 
the PID responds to the environmental change of $T_{a}^{i n, S}$ in shorter settling time. A settling area $A_{S P}$ is defined in Eq. (4) to quantify the accumulated residuals over $\left(t_{A C}\right.$, $\left.t_{S P}\right)$ due to the change of inlet air temperature, and has to be minimized to obtain the optimal $\left(T_{a, C}^{i n, S}, d K_{i}\right)$ data pairs from examples:

$$
A_{S P}=\int_{t_{A C}}^{t_{S P}}\left|T_{o}^{a v, S}(t)-T_{o}^{r e f, S}\right| d t
$$

where, $t_{A C}$ is the starting change time of $T_{a}^{i n, S}$, i.e., $t_{A C}=1000 \mathrm{~s}$ in our case, and $t_{S P}$ is the end time of the PID settling period, i.e., $t_{S P}=1800 \mathrm{~s}$ (as suggested by the scenarios plotted in Fig. 5). At full power nominal conditions, the average drift within the time interval of $[1000,1800] \mathrm{s}$ is $0.067^{\circ} \mathrm{C}$ and the accumulated residual is, thus, equal to 53.6. For the conservative consideration of the optimal data pairs, 300 is assumed as the acceptable value of $A_{S P}$.

In this step, three groups of $n_{2}=1000$ simulations each of the LBE-XADS are run, each one devised to obtain the input-output data pairs, for finding the optimal $d K_{p}, d K_{i}$, and $d K_{d}$, respectively:

\section{1) Group 1:}

a. Set the initial inlet air temperature $T_{a}^{i n, S}(0)$ equal to $20^{\circ} \mathrm{C}$ and start the simulation.

b. At $t=1000 \mathrm{~s}$, sample a random value of $T_{a, C}^{i n, S}$ uniformly distributed in $[0,30]^{\circ} \mathrm{C}$ and the value of the change of the gain $K_{p}$ from a uniform distribution $U \sim[-50$, 50), whereas, the $K_{i}$ and $K_{d}$ are kept equal to the reference values 0.2 and 0 , respectively; continue the present simulation till the mission time $t_{M}=3000 \mathrm{~s}$.

c. Calculate the value of the performance index, $\bar{e}_{S S}$, and represent its values on the three-dimensional diagrams, i.e., $\left(T_{a, C}^{i n, S}, d K_{p}, \bar{e}_{S S}\right)$. When the calculated value is smaller than $0.07^{\circ} \mathrm{C}$, the input-output data pair is labelled as optimal to be utilized hereafter. 


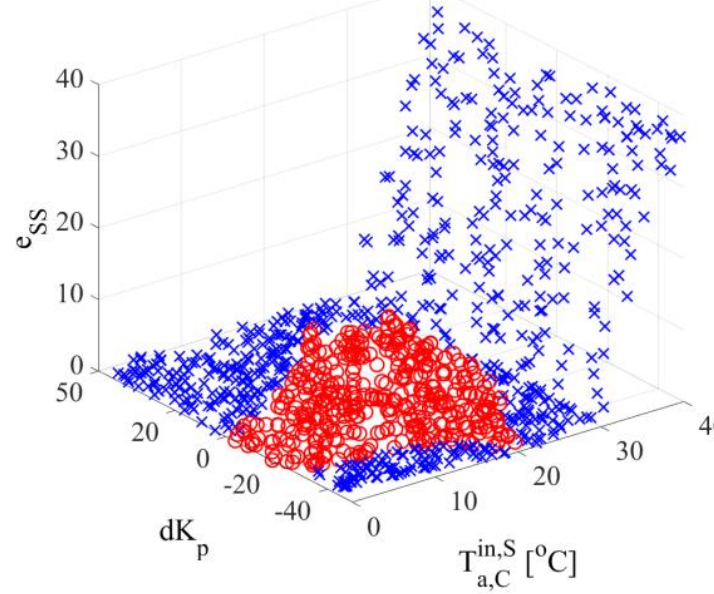

(a)

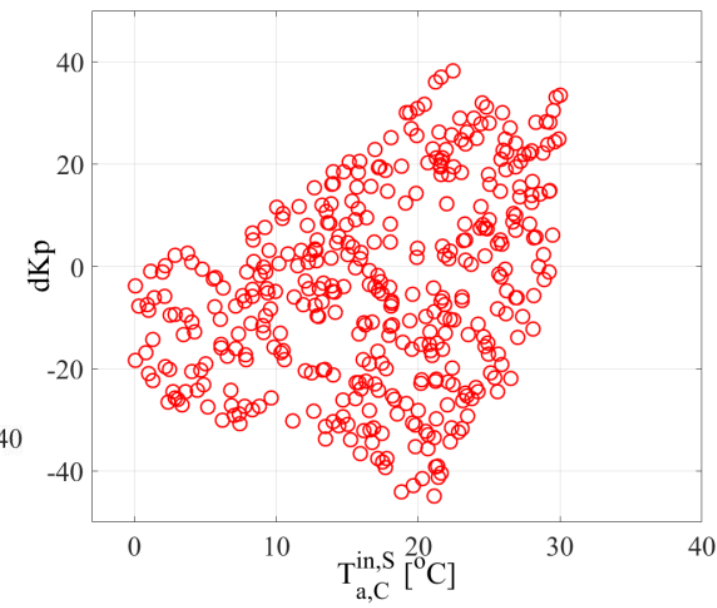

(b)

Fig. 9. Results of the $n_{2}=1000$ runs for the Group 1: (a) three-dimensional plot of $\left(T_{a, C}^{i n, S}, d K_{p}, \bar{e}_{S S}\right)$, where circles are the value of $\bar{e}_{S S}$ smaller than $0.07^{\circ} \mathrm{C}$ and crosses are the value of $\bar{e}_{S S}$ exceeding $0.07^{\circ} \mathrm{C}$; (b) optimal $\left(T_{a, C}^{i n, S}, d K_{p}\right.$ ) data pairs (circles of Fig. $9(a)$ )

Fig. 9(a) shows that the value of $\bar{e}_{S S}$ is smaller than $0.07^{\circ} \mathrm{C}$ if the inlet air temperature changes to values smaller than $30^{\circ} \mathrm{C}$. The sparsity of the optimal inputoutput data pairs $\left(T_{a, C}^{i n, S}, d K_{p}\right)$ (circles in Figs. 9(a) and (b)) suggests the lack of a univocal mapping correlation of $K_{p}$ with changes of $T_{a}^{i n, S}$ and, thus, defines the weakness of $K_{p}$ in controlling the physical dynamics under variable environmental conditions.

Whereas, if $T_{a, C}^{i n, S}$ is larger than $30^{\circ} \mathrm{C}$ (i.e., out of the system design operational limits), $\bar{e}_{S S}$ exceeds by far the acceptable value of $0.07^{\circ} \mathrm{C}$, such that no optimal inputoutput data pairs can be expected. As already said, this phenomenon is due to the fact that the maximum air mass flow rate $\Gamma_{a, \max }$ cannot meet the required value when $T_{a, C}^{i n, S}$ exceeds $30^{\circ} \mathrm{C}$.

\section{2) Group 2:}

a. Set the initial inlet air temperature $T_{a}^{i n, S}(0)$ equal to $20^{\circ} \mathrm{C}$ and start the simulation.

b. At $t=1000 \mathrm{~s}$, sample a random value of $T_{a, C}^{i n, S}$ uniformly distributed in $[0,30]^{\circ} \mathrm{C}$ and the value of the change of the gain $K_{i}$ from a uniform distribution $U \sim(-0.2$, 0.4 ), whereas the $K_{p}$ and $K_{d}$ are kept equal to the reference values 50 and 0 , 
respectively; continue the present simulation till the mission time $t_{M}=3000 \mathrm{~s}$.

c. Calculate the value of the performance index, $A_{S P}$, and represent the values of the performance index on the three-dimensional diagrams, i.e., $\left(T_{a, C}^{i n, S}, d K_{i}, A_{S P}\right)$. When the calculated value is smaller than 300 , the input-output data pair is labelled as optimal and stored for future utilization.

Fig. 10(a) shows the values of $A_{S P}$ increasing with $(i)$ increasing $d K_{i}$ and decreasing $T_{a, C}^{i n, S}$, or (ii) decreasing $d K_{i}$ and increasing $T_{a, C}^{i n, S}$. When the sampled $T_{a, C}^{i n, S}$ is larger than $30^{\circ} \mathrm{C}$ (i.e., out of the system design operational limits), the value of the calculated $A_{S P}$ is much larger than 300 , no matter the value of $d K_{i}$.

Fig. 10(b) shows the optimal $\left(T_{a, C}^{i n, S}, d K_{i}\right)$ (i.e., whose $A_{S P}$ is below the acceptable value) and the existence of an explicit mapping relationship between $d K_{i}$ and $T_{a, C}^{i n, S}$. This makes this value crucial for adjusting the hybrid fuzzy-PID gains to the varying environmental conditions and controlling the system dynamics.

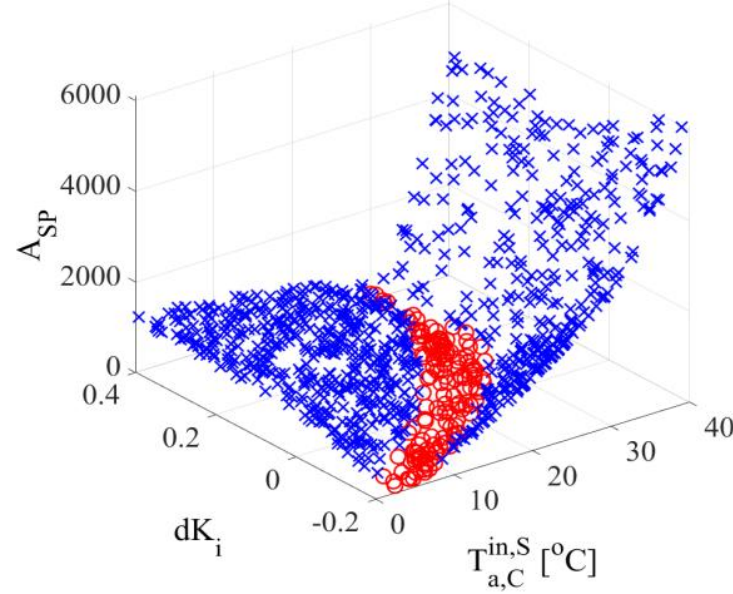

(a)

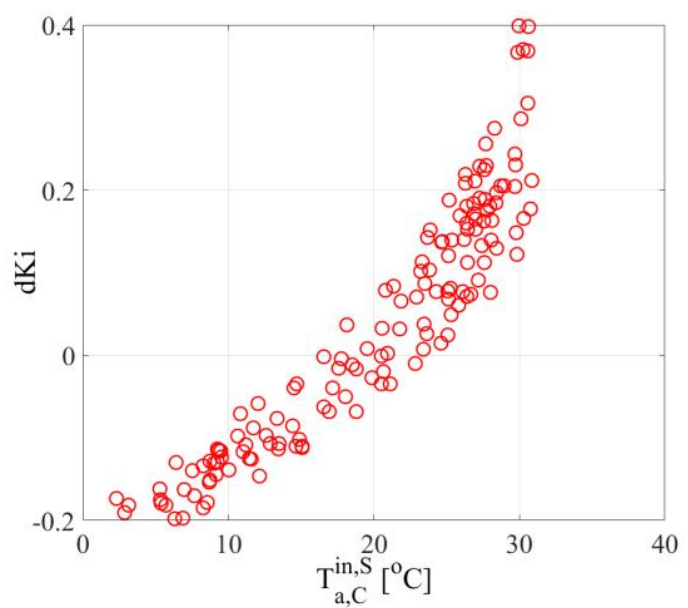

(b)

Fig. 10. Results of the $n_{2}=1000$ runs for the Group 2: (a) three-dimensional plot of $\left(T_{a, C}^{i n, S}, d K_{i}\right.$, $\left.A_{S P}\right)$, where circles are the value of $A_{S P}$ smaller than 300 and crosses are the value of $A_{S P}$ exceeding 300; (b) mapping of the optimal $\left(T_{a, C}^{i n, S}, d K_{i}\right)$ data pairs

\section{3) Group 3:}

a. Set the initial inlet air temperature $T_{a}^{i n, S}(0)$ equal to $20^{\circ} \mathrm{C}$ and start the simulation. 
b. At $t=1000 \mathrm{~s}$, sample a random value of $T_{a, C}^{i n, S}$ uniformly distributed in $[0,30]^{\circ} \mathrm{C}$ and the value of the change of the gain $K_{d}$ from a uniform distribution $U \sim(-0.2$, 0.4 ), whereas the $K_{p}$ and $K_{i}$ are kept equal to the reference values 50 and 0.2 , respectively; continue the present simulation till the mission time $t_{M}=3000 \mathrm{~s}$.

c. Calculate the value of the performance index, $\bar{e}_{S S}$, and represent values on the three-dimensional diagrams, i.e., $\left(T_{a, C}^{i n, S}, d K_{d}, \bar{e}_{S S}\right)$. When the calculated value is smaller than $0.07^{\circ} \mathrm{C}$, the input-output data pair is labelled as optimal to be utilized hereafter.

Fig. 11(a) shows that the value of $\bar{e}_{S S}$ is smaller than $0.07^{\circ} \mathrm{C}$ if the inlet air temperature changes to values smaller than $30^{\circ} \mathrm{C}$. The sparsity of the optimal inputoutput data pairs $\left(T_{a, C}^{i n, S}, d K_{d}\right)$ (circles in Figs. 11(a) and (b)) suggests the lack of a univocal mapping correlation of $K_{d}$ with changes of $T_{a}^{i n, S}$ and, thus, defines the weakness of $K_{d}$ in controlling the physical dynamics under variable environmental conditions.

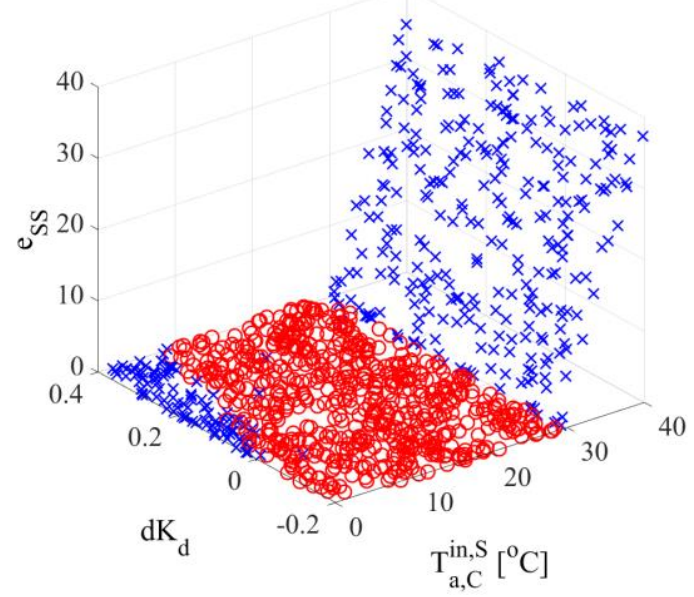

(a)

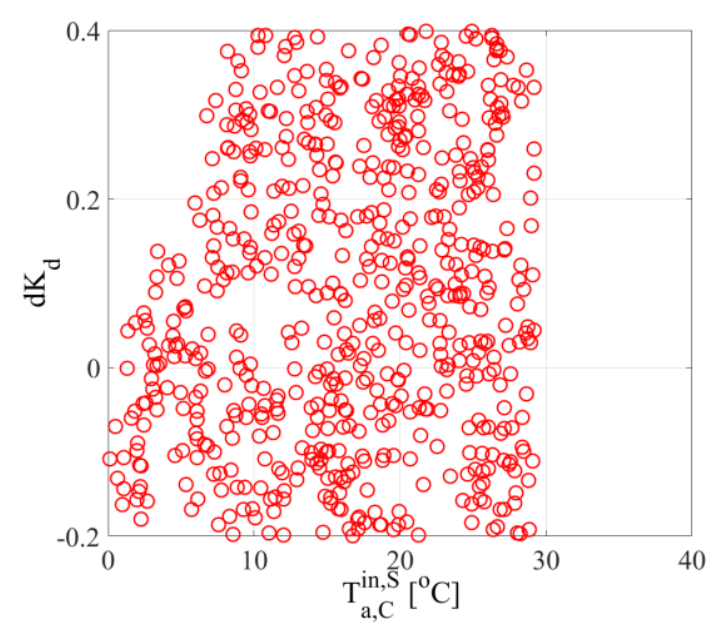

(b)

Fig. 11. Results of the $n_{2}=1000$ runs for the Group 3: (a) three-dimensional plot of $\left(T_{a, C}^{i n, S}, d K_{d}\right.$, $\bar{e}_{S S}$ ), where circles are the value of $\bar{e}_{S S}$ smaller than $0.07^{\circ} \mathrm{C}$ and crosses are the value of $\bar{e}_{S S}$ exceeding $0.07^{\circ} \mathrm{C}$; (b) mapping of the optimal $\left(T_{a, C}^{i n, S}, d K_{d}\right)$ data pairs (circles in Fig. 11(a))

Whereas, with the fixed initial value of inlet air temperature $T_{a}^{i n, S}(0)$ equal to $20^{\circ} \mathrm{C}$, if $T_{a, C}^{i n, S}$ is larger than $30^{\circ} \mathrm{C}$ (i.e., out of the system design operational limits), $\bar{e}_{S S}$ 
exceeds by far the acceptable value of $0.07^{\circ} \mathrm{C}$, such that no optimal input-output data pairs can be expected. Such a phenomenon is probably due to the fact that the maximum air mass flow rate $\Gamma_{a, \text { max }}$ cannot meet the required value when $T_{a, C}^{i n, S}$ exceeds $30^{\circ} \mathrm{C}$.

In conclusion, we can claim that, for this case study, $K_{p}$ and $K_{d}$ play a negligible role in the adaptation of the controller when working under varying environmental conditions, whereas $K_{i}$ is sensitive to changes of the environmental conditions and, therefore, an appropriate setting of $K_{i}$ to different $T_{a, C}^{i n, S}$ can improve the adaptive properties of the controller for maintaining $T_{o}^{a v, S}$ at the desired reference value. As a result, the controller block of Fig. 6 is transformed to that shown in Fig. 12.

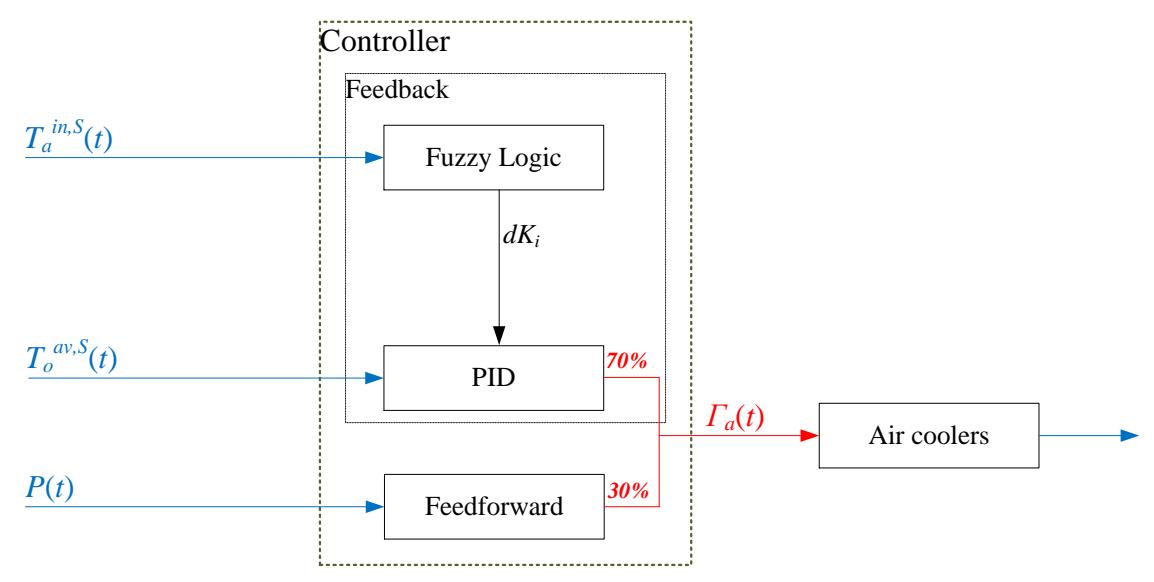

Fig. 12. Optimized structure of the controller under variable inlet air temperature

\section{Step 2: Generation of the fuzzy sets and fuzzy rules}

The grid-type fuzzy partitioning approach is used to generate the fuzzy sets and fuzzy rules for the fuzzy reasoning between the input $T_{a, C}^{i n, S}$ and the output $d K_{i}$, as shown in Fig. 13: 


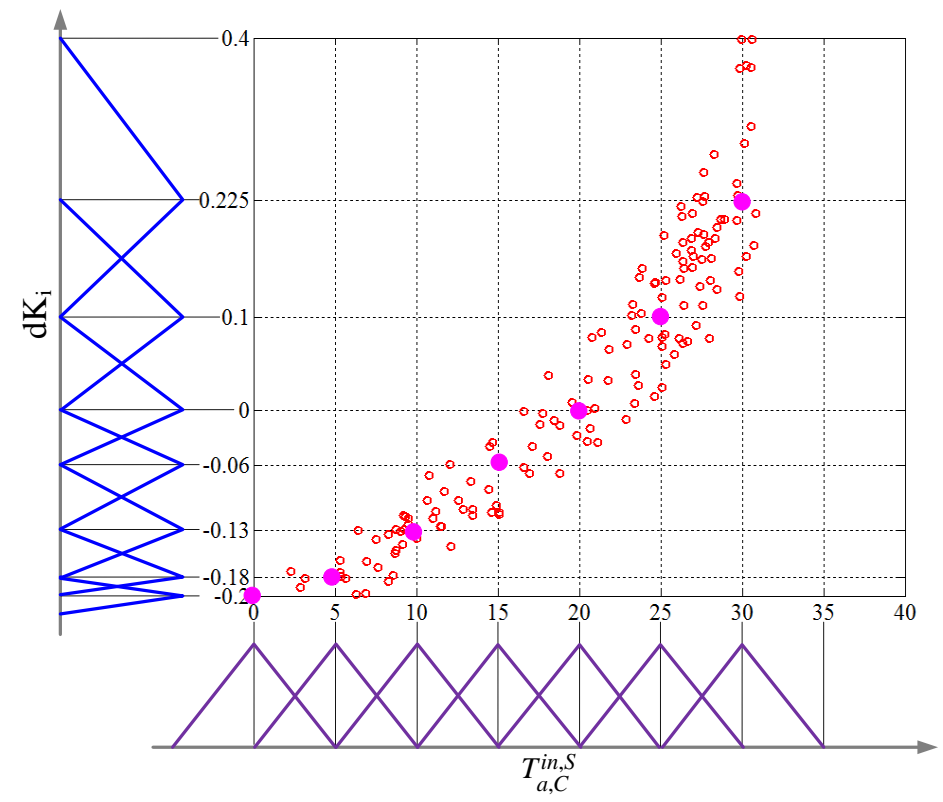

Fig. 13. Generation of the fuzzy sets by the grid-type fuzzy partitioning approach

1) Evenly partition the antecedents domain $T_{a, C}^{i n, S}=[0,30]^{\circ} \mathrm{C}$ into reasonably small sets with given triangular membership functions; we partitioned the input support in seven sets $T_{j}, j=1,2, \ldots, 7,[-5,0,5],[0,5,10],[5,10,15],[10,15,20],[15,20,25]$, $[20,25,30],[25,30,35]^{\circ} \mathrm{C}$ (see Fig. 14 ) (See the Appendix for a sensitivity analysis that justifies the choice of the number of the fuzzy sets).

2) Collect $\left(T_{a, C}^{i n, S}, d K_{i}\right)$ of the seven central points of the optimal sets.

3) Generate triangular output fuzzy sets $I_{j}, j=1,2, \ldots, 7$, whose largest degree of membership is centered on the $d K_{i}$ of the data pairs $\left(T_{a, C}^{i n, S}, d K_{i}\right)$ of Step (2). The seven output fuzzy sets, then, are $[-0.22,-0.2,-0.18],[-0.2,-0.18,-0.13],[-0.18$, $0.13,-0.06],[-0.13,-0.06,0],[-0.06,0,0.1],[0,0.1,0.225],[0.1,0.225,0.4]$ (see Fig. 14).

4) Define the fuzzy rules $R_{j}, j=1,2, \ldots, 7$, that define how to match antecedents and consequents, that, in our case, take the form:

$R_{j}$ : IF ( $T_{a, C}^{i n, S}$ belong to $\left.T_{j}\right)$ THEN $\left(d K_{i}\right.$ belong to $\left.I_{j}\right)$. 

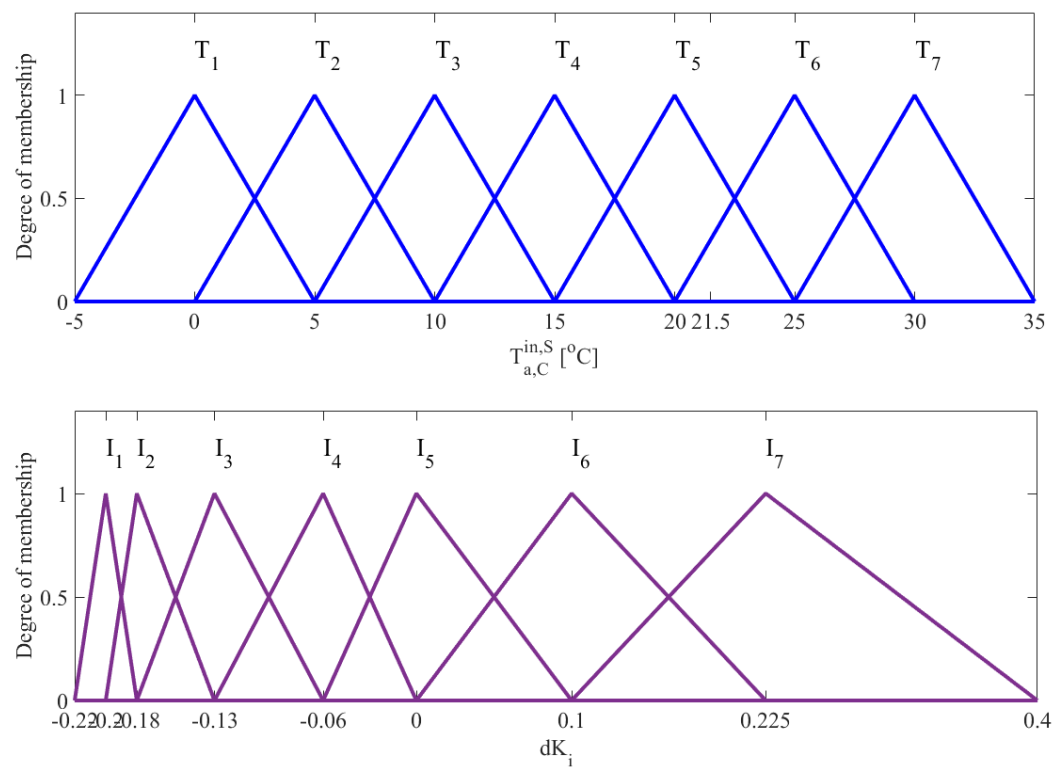

Fig. 14. The fuzzy sets generated from the grid-type partitioning approach

Defuzzification of the consequents is performed by the centroid calculation of a Mamdani-style fuzzy system inference [33]-[35]. The fuzzy conclusion of the consequent $y\left(d K_{i}\right)$ corresponding to an antecedent is a fuzzy set $Y$ constituted by the membership function $\mu_{Y}\left(y\left(d K_{i}\right)\right)$. Fig. 15 shows an example of fuzzy conclusion.
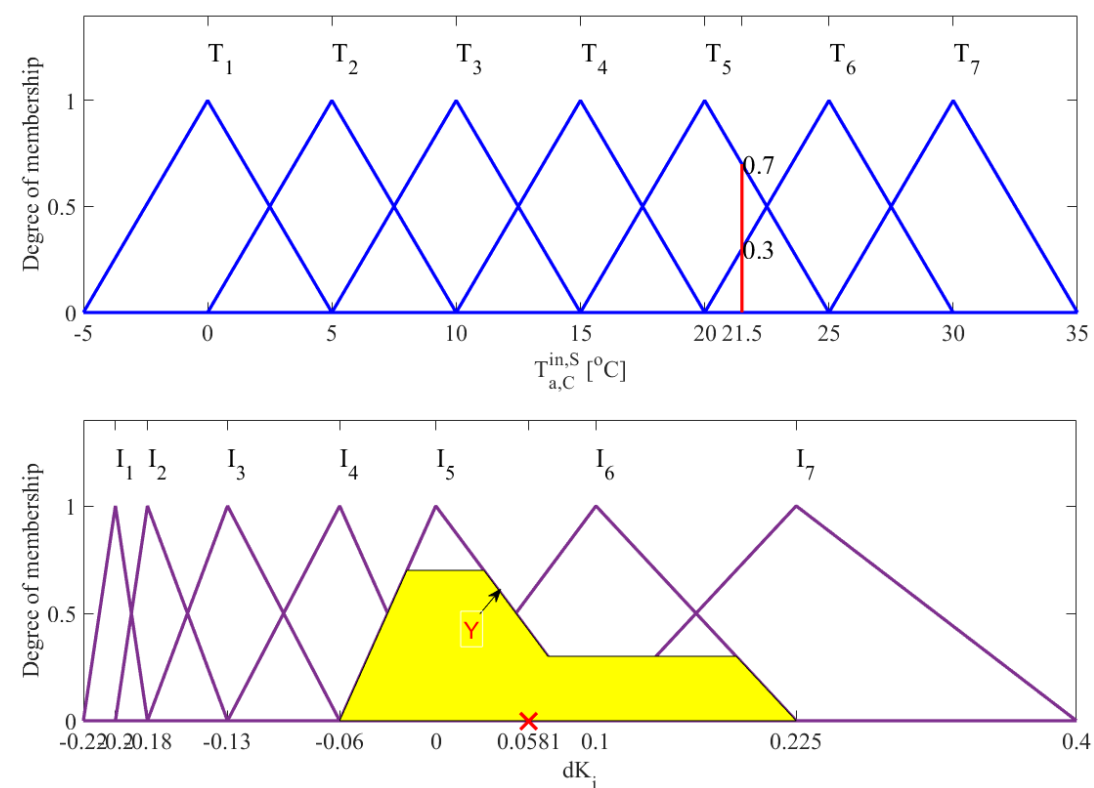

Fig. 15. Example of the consequent $d K_{i}$ calculation: the value 0.0581 is the centroid of the weighted area of the two fuzzy sets activated by the antecedent $T_{a, C}^{i n, S}=21.5^{\circ} \mathrm{C}$

For example, $T_{a}^{i n, S}$ changes to $21.5^{\circ} \mathrm{C}$ at time $t=1000 \mathrm{~s}$ and yields the fuzzy 
membership values 0.7 in $T_{5}$ and 0.3 in $T_{6}$, respectively:

$$
T_{a, C}^{i n, S(21.5)}:\left(0.7 \text { in } T_{5}, 0.3 \text { in } T_{6}\right) .
$$

Thus, the weights 0.7 and 0.3 are applied to $T_{5}$ and $T_{6}$ given for the antecedent $T_{a, C}^{i n, S(21.5)}$.

The aggregated output fuzzy set $Y$ is generated with the weights 0.7 in $I_{5}$ and 0.3 in $I_{6}$ (see shadowed area in Fig. 15), whose centroid is equal to 0.0581 that is assumed as consequent $d K_{i}$ to a change of $T_{a, C}^{i n, S}$ to $21.5^{\circ} \mathrm{C}$.

\section{The Variable-Gain PID Controller}

In this Section, a variable-gain PID controller of literature [38] is defined for comparing its controlling capability with that of the proposed hybrid fuzzy-PID controller. In Section II.A, it has been pointed out that $K_{i}$ is sensitive, whereas, $K_{p}$ and $K_{d}$ are insensitive to changes of the environmental conditions, therefore, the PID controller will only vary the $K_{i}$ as in Eq. (5) [38].

Notice that the pivotal values of $T_{a, C}^{i n, S}$ used to build the best fitting linear interpolation curve are $\left(15^{\circ} \mathrm{C}, K_{i}=0.135\right)$ and $\left(25^{\circ} \mathrm{C}, K_{i}=0.30\right)$, that are two optimal data pairs of Fig. 10(b) defining a likely interval of temperatures under which the plant is operated. Thus, the expression of $K_{i}$ can be as (see Fig. 16):

$$
K_{i}\left(T_{a, C}^{i n, S}\right)= \begin{cases}0.003, & 0^{\circ} C \leq T_{a, C}^{i n, S} \leq 7^{\circ} C \\ 0.165 \cdot\left(T_{a, C}^{i n, S}-25\right)+0.3, & 7^{\circ} C<T_{a, C}^{i n, S} \leq 30^{\circ} C\end{cases}
$$

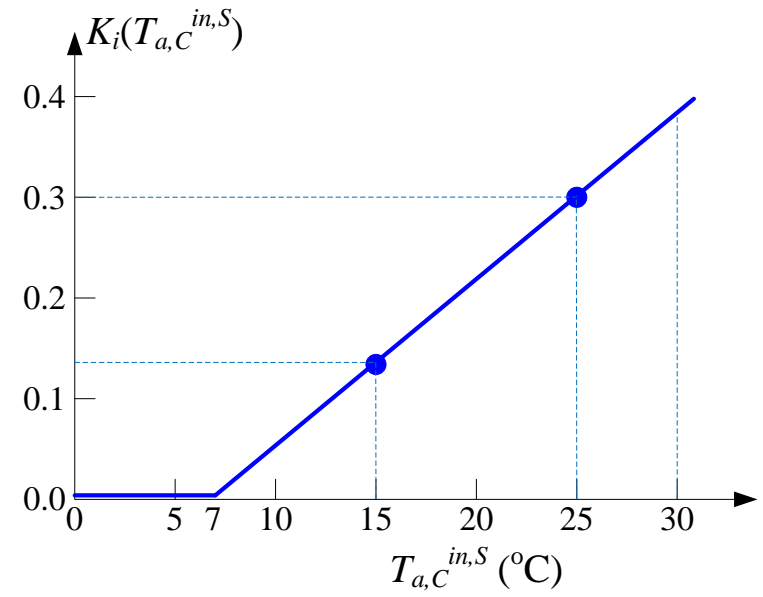

Fig. 16. Generation of the expression of $K_{i}$ in terms of $T_{a, C}^{i n, S}$ 


\section{RESULTS}

In Section IV.A, the capability of the hybrid fuzzy-PID of Section III is benchmarked with the originally proposed PID controller with respect to a batch of sample simulations among the $n_{2}$ (described in Section III.A) that were used to train the algorithm for learning the rules. The practical usefulness of the proposed hybrid fuzzyPID controller is, then, demonstrated with respect to a realistic scenario of daily cycle of inlet air temperatures, under normal environmental conditions and also transients due to wrong measurements of the temperature sensor (in Sections IV.B and IV.C, respectively).

\section{A. Test on the Training Examples}

We sample 18 random trials from the $n_{2}$ runs of the LBE-XADS Simulink model that were generated to train the rule generation algorithm, as described in Section III.B. As shown in Fig. 17(a), despite that the performance of the original PID controller (line with triangles) and the linearly variable $K_{i}$ PID controller (line with diamonds) are acceptable for all of the 18 samples, the settling areas $A_{S P}$ obtained with the hybrid fuzzy-PID controller (line with dots) are in most cases smaller than those obtained with the original PID and with the linearly variable $K_{i}$ PID (also can be seen in Table I): in general terms, the optimized hybrid fuzzy-PID smooths down the step response caused by the change of the environmental conditions. At the same time, if $T_{a}^{i n, S}$ changes to a random value within the interval of $[8,30.5]^{\circ} \mathrm{C}$, the average steady-state drift $\bar{e}_{S S}$ is smaller with the hybrid fuzzy-PID (line with dots) than with the original PID (line with triangles) and with the linearly variable $K_{i}$ PID (line with diamonds), as shown in Fig. 17(b). In particular, the larger the temperature, the better the performance of the hybrid fuzzy-PID with respect to the original PID (see cases number 17 and 18 with $T_{a, C}^{\text {in,S }}$ equal to $29.98^{\circ} \mathrm{C}$ and $30.45^{\circ} \mathrm{C}$, respectively), not only because $\bar{e}_{S S}$ decreases (from 0.157 to 0.0405 and from 1.16 to 0.0490 , respectively), but also because the hybrid fuzzy-PID is capable of bringing back the secondary average coolant temperature to the reference value equal to $300^{\circ} \mathrm{C}$, whereas the original PID cannot. 
It is worth pointing out that neither the hybrid fuzzy-PID nor the original PID can safely control the system when $T_{a}^{i n, S}$ changes to a value larger than $31^{\circ} \mathrm{C}$, as mentioned in Section III.B.b.
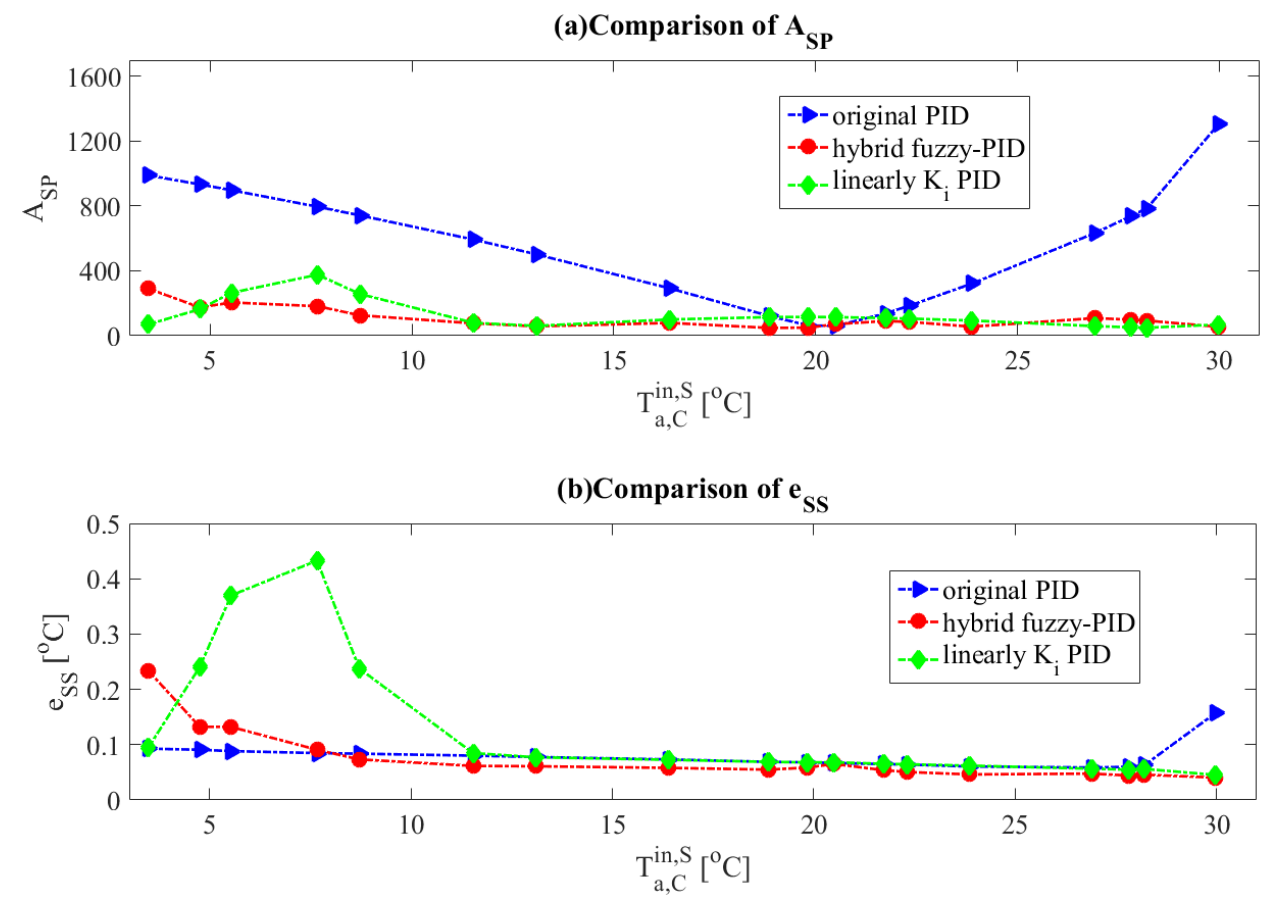

Fig. 17. Comparison between results of samples of the $T_{o}^{a v, S}$ evolution with the optimized hybrid fuzzy-PID controller (line with dots), with linearly variable $K_{i}$ PID (line with diamonds) and with the original PID (line with triangles): (a) comparison of $A_{S P}$; (b) comparison of $\bar{e}_{S S}$

\section{TABLE I}

comparison of the performance indexes obtained from samples of the $T_{o}^{a v, S}$ evolutions with the hybrid fuzzy PID, the linear variable $\mathrm{K}_{\mathrm{i}}$ PID and the original PID

\begin{tabular}{|c|c|c|c|c|c|c|c|}
\hline \multirow{2}{*}{ No. } & \multirow{2}{*}{$T_{a, C}^{\text {in,S }}\left({ }^{\circ} \mathrm{C}\right)$ at } & \multicolumn{2}{|c|}{ Original PID } & \multicolumn{2}{c|}{ Linear $K_{i}$ PID } & \multicolumn{2}{c|}{ Hybrid fuzzy-PID } \\
\cline { 3 - 7 } & $t=1000 \mathrm{~s}$ & $A_{S P}$ & $\bar{e}_{S S}\left({ }^{\circ} \mathrm{C}\right)$ & $A_{S P}$ & $\bar{e}_{S S}\left({ }^{\circ} \mathrm{C}\right)$ & $A_{S P}$ & $\bar{e}_{S S}\left({ }^{\circ} \mathrm{C}\right)$ \\
\hline 1 & 3.474 & 989.7 & 0.0929 & 69.64 & 0.0947 & 290.8 & 0.233 \\
\hline 2 & 4.751 & 934.1 & 0.0907 & 163.8 & 0.241 & 173.9 & 0.134 \\
\hline 3 & 5.531 & 898.1 & 0.0878 & 264.4 & 0.370 & 205.1 & 0.133 \\
\hline 4 & 7.663 & 796.0 & 0.0851 & 376.2 & 0.433 & 181.3 & 0.0913 \\
\hline 5 & 8.716 & 742.6 & 0.0848 & 257.1 & 0.238 & 125.3 & 0.0742 \\
\hline 6 & 11.54 & 592.2 & 0.0806 & 78.54 & 0.0848 & 76.14 & 0.0618 \\
\hline 7 & 13.09 & 501.8 & 0.0777 & 60.74 & 0.0773 & 57.82 & 0.0607 \\
\hline 8 & 16.38 & 293.1 & 0.0734 & 99.94 & 0.0727 & 79.02 & 0.0573 \\
\hline 9 & 18.87 & 120.2 & 0.0688 & 114.7 & 0.0689 & 47.86 & 0.0550 \\
\hline 10 & 19.83 & 62.53 & 0.0685 & 115.7 & 0.0680 & 49.84 & 0.0582 \\
\hline 11 & 20.50 & 61.61 & 0.0680 & 114.2 & 0.0682 & 71.95 & 0.0651 \\
\hline 12 & 21.73 & 136.8 & 0.0640 & 109.0 & 0.0654 & 90.43 & 0.0538 \\
\hline 13 & 22.33 & 184.9 & 0.0833 & 105.3 & 0.0645 & 84.63 & 0.0510 \\
\hline 14 & 23.87 & 321.3 & 0.0597 & 93.33 & 0.0621 & 55.57 & 0.0456 \\
\hline 15 & 26.92 & 634.0 & 0.0583 & 59.02 & 0.0565 & 108.7 & 0.0474 \\
\hline 16 & 28.21 & 786.1 & 0.0631 & 51.35 & 0.0550 & 93.02 & 0.0461 \\
\hline 17 & 29.98 & 1305 & 0.157 & 49.07 & 0.0561 & 54.39 & 0.0405 \\
\hline 18 & 30.45 & 1685 & 1.16 & 68.50 & 0.0454 & 43.21 & 0.0490 \\
\hline
\end{tabular}




\section{B. A Realistic Daily Air Temperature Scenario}

For demonstration purpose, let us assume a realistic daily $T_{a}^{i n, S}$ fluctuation as that in Fig. 18, where the initial value $T_{a}^{i n, S}(0)$ is equal to $20^{\circ} \mathrm{C}$ corresponding to the nominal operating condition of the LBE-XADS and, the actual $T_{a}^{i n, S}$ is fed to the Simulink model of the LBE-XADS, to test the hybrid fuzzy-PID controller working under real-time varying environmental conditions, at each 100s (i.e., smaller than the original PID resettling period, equal to 800s as shown in Fig. 5). This is done with the purpose of illustrating the capability of the hybrid fuzzy-PID to reduce residual $e(t)$ even when the system is fed with high frequency changes of $T_{a}^{i n, S}$ that do not allow it to reach a new steady state before a new measurement is collected. Under these assumptions, Fig. 19 shows that $T_{o}^{a v, S}$ can be kept close to the desired reference level of $300^{\circ} \mathrm{C}$ with both the hybrid fuzzy-PID controller (line with dots), the linear variable $K_{i}$ PID controller (line with diamonds) and the original PID (line with triangles).

The proposed hybrid fuzzy-PID feedback controller reduces the drift $\bar{e}_{S S}=0.1376^{\circ} \mathrm{C}$ of the original PID and $\bar{e}_{S S}=0.1027^{\circ} \mathrm{C}$ of the variable $K_{i}$ PID to $\bar{e}_{S S}=0.0600^{\circ} \mathrm{C}$, showing that in this case the hybrid fuzzy-PID controller performs better than the original PID controller, under varying environmental conditions.

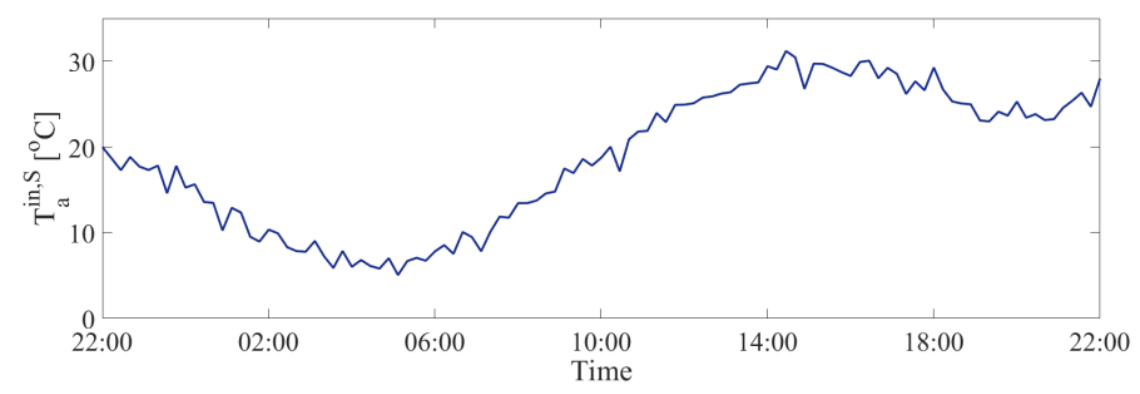

Fig. 18. Realistic daily $T_{a}^{i n, S}$ fluctuation pattern, embedded into the simulation of the LBE-XADS 


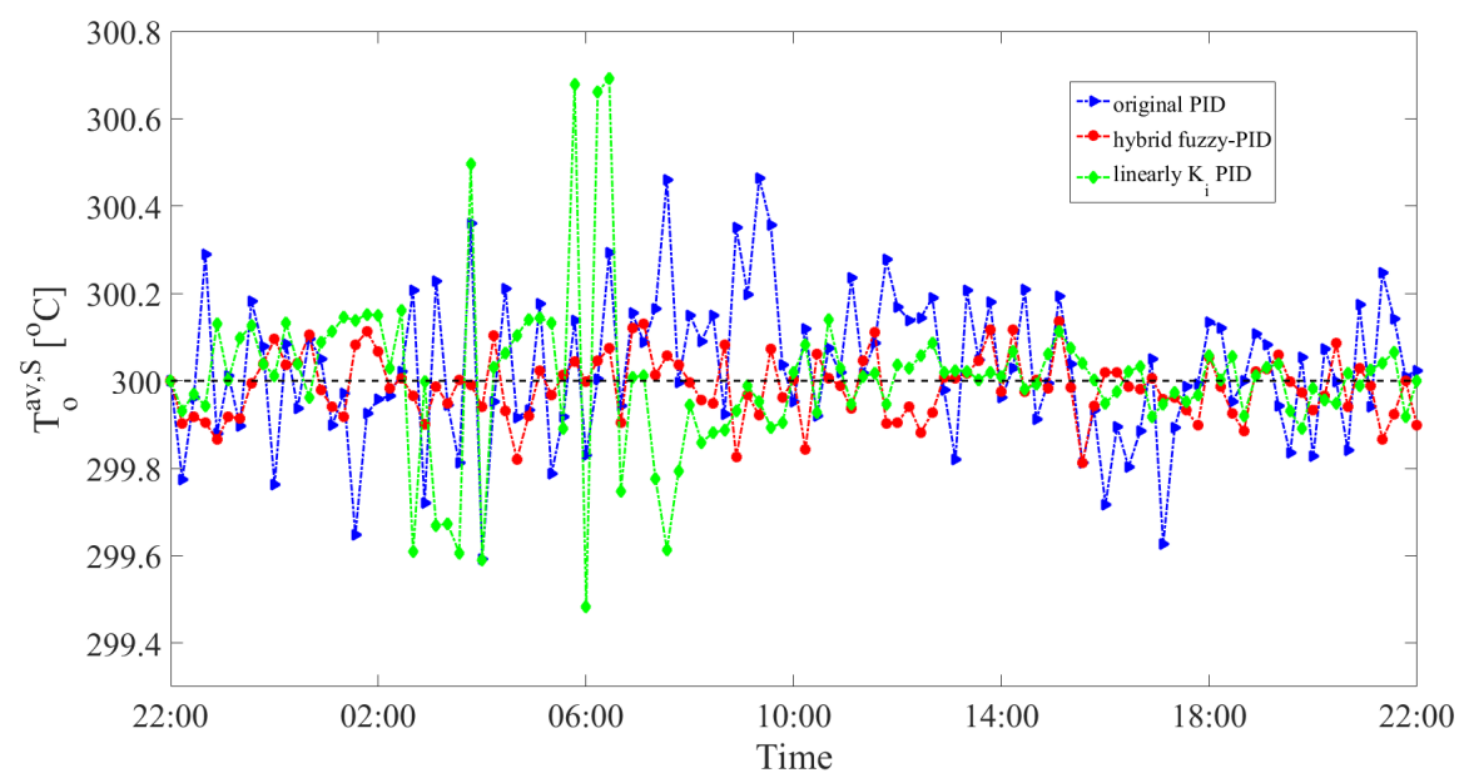

Fig. 19. Realistic daily simulation of the $T_{o}^{a v, S}$ evolution with the optimized hybrid fuzzy-PID controller (line with dots), with the linear variable $K_{i}$ PID (line with diamonds) and with the original PID (line with triangles), at the normal operating conditions

\section{Sensors Failure Scenarios}

Adaptivity of the CPS to sensors failures has also been analyzed for demonstration purpose. Indeed, transients due to wrong measurements can affect the NPP dynamics, since any transient, even though on the secondary side, can propagate to the primary coolant system and, eventually to the reactor core [36]. With no intention to treat a full spectrum of failures, for the purpose of exemplification, two failures are considered:

1) Drift: at $06: 00, T_{a}^{i n, S}$ drifts up to $28^{\circ} \mathrm{C}$ that is reached at roughly $06: 07$, and, then, drops back to the normal environmental condition at 06:10 (see Fig. 20(b));

2) Bias: within the time interval between 18:00 and 18:05, the measured $T_{a}^{i n, S}$ is biased (because of a sensor bias or a malicious cyber attack) with an increased noise distributed as $\mathrm{U} \sim(-10,1)^{\circ} \mathrm{C}$ (see Fig. $20(\mathrm{c})$ ). 

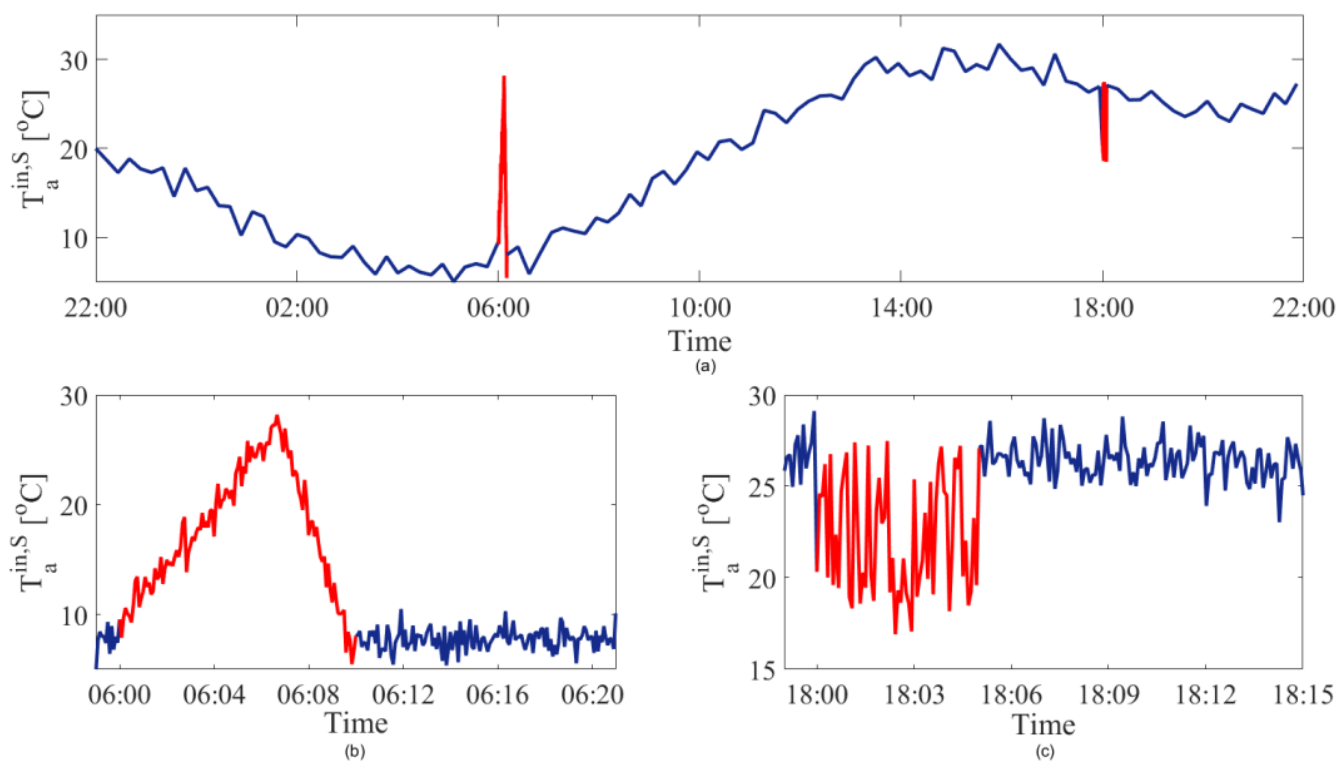

Fig. 20. Sketch of the assumed sensors failures: (a) the assumed daily $T_{a}^{\text {in,s }}$ profile; (b) drift of $T_{a}^{i n, S}$ within [06:00, 06:10]; (c) bias of $T_{a}^{i n, S}$ within [18:00, 18:05]

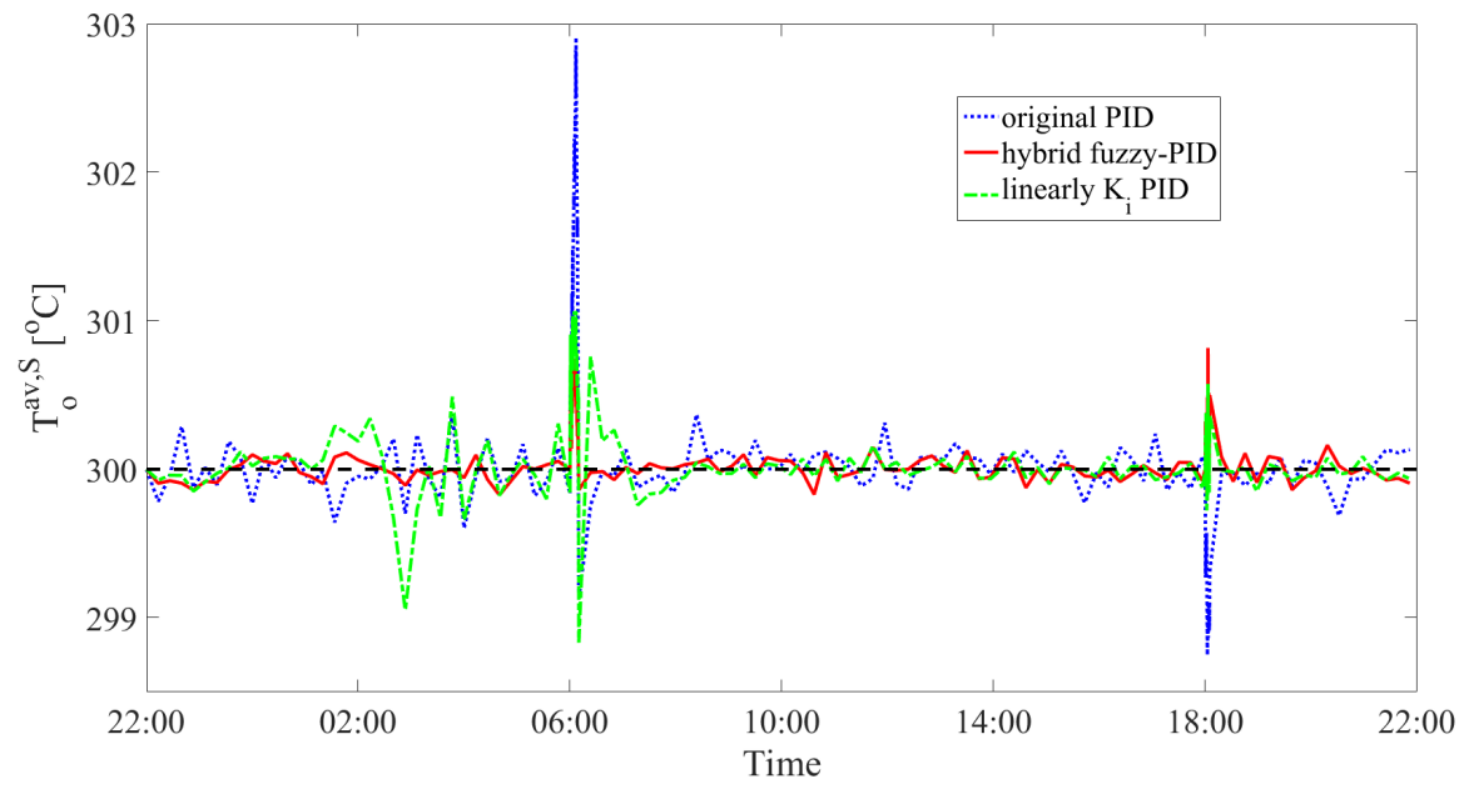

Fig. 21. $T_{o}^{a v, S}$ evolution with the optimized hybrid fuzzy-PID controller (continuous line), with the linear variable $K_{i}$ PID (dashed line) and with the original PID (dotted line), under the assumed sensors failure conditions

Fig. 21 shows that under the two assumed $T_{a}^{i n, S}$ sensors failures, the $T_{o}^{a v, S}$ fluctuations provided by the linear variable $K_{i}$ PID (dashed line) and by the original PID (dotted line) are larger than those of the hybrid fuzzy-PID controller (continuous line). 
Let us focus on the local details of the $T_{o}^{a v, S}$ evolutions within the two spans of transients, including the post-transient adaptivity periods. For the transient periods and post-transient periods, the average drifts obtained with the hybrid fuzzy-PID controller are much smaller than those obtained with the original PID (see TABLE II).

\section{TABLE II}

Comparison of the average drifts of the $T_{o}^{a v, S}$ evolutions with the hybrid fuzzy PID, the linear variable $\mathrm{K}_{\mathrm{i}}$ PID and the original PID, under the transient operating conditions

\begin{tabular}{|c|c|c|c|c|}
\hline \multirow{3}{*}{$\begin{array}{c}\text { Transient } \\
\text { type }\end{array}$} & $\begin{array}{c}\text { Time } \\
\text { interval }\end{array}$ & Original PID & $\begin{array}{c}\text { Variable } K_{i} \\
\text { PID }\end{array}$ & $\begin{array}{c}\text { Hybrid } \\
\text { fuzzy-PID }\end{array}$ \\
\cline { 3 - 5 } Drift & $\begin{array}{c}{[06: 00,} \\
06: 10]\end{array}$ & 1.4040 & 0.7345 & 0.4268 \\
\cline { 2 - 5 } & $\begin{array}{c}{[06: 10,} \\
06: 20]\end{array}$ & 1.2464 & 0.3363 & 0.1555 \\
\hline \multirow{5}{*}{ Bias } & $\begin{array}{c}{[18: 00,} \\
18: 05]\end{array}$ & 0.8439 & 0.1852 & 0.2622 \\
\cline { 2 - 5 } & $\begin{array}{c}{[18: 05,} \\
18: 15]\end{array}$ & 0.4327 & 0.0770 & 0.1533 \\
\hline
\end{tabular}

Figs. 22 and 23 zoom the $T_{o}^{a v, S}$ evolutions obtained from the simulations with the optimized hybrid fuzzy-PID controller, with the linear variable $K_{i} \mathrm{PID}$ and with the original PID, under the transients (a) and (b), respectively. The original PID cannot adaptively respond to the rapid fluctuations of the environmental conditions (dotted line with triangle) and requires roughly 600 s (from $06: 10$ to $06: 20$ ) to recover the system stability under sensor drift circumstances (see Fig. 22). The linearly variable $K_{i}$ PID can rapidly respond to the transient and recover the system stability from the drift failure scenario as shown in Fig. 21, however, $T_{o}^{a v, S}$ largely deviates from the reference value with an $\bar{e}_{S S}$ equal to $0.7345^{\circ} \mathrm{C}$ within the transient period (dashed line with diamonds) and an $\bar{e}_{S S}$ equal to $0.3363^{\circ} \mathrm{C}$ within the recovery period. Despite an $\bar{e}_{S S}$ equal to $0.4268^{\circ} \mathrm{C}$ within the transient period (continuous line with dots), $T_{o}^{a v, S}$ can promptly recover the nominal temperature with an $\bar{e}_{S S}$ equal to $0.1555^{\circ} \mathrm{C}$, which is much smaller than that obtained from the original PID $\left(1.2464^{\circ} \mathrm{C}\right)$ (see TABLE II).

Similarly, the original PID poorly adapts to the sensor bias failure scenario (see Fig. 23, dotted line with triangle) and yields an $\bar{e}_{S S}$ equal to $0.8439^{\circ} \mathrm{C}$. Despite larger $\bar{e}_{S S}$ during both the transient and the post-transient periods $\left(\bar{e}_{S S}\right.$ equal to $0.2622^{\circ} \mathrm{C}$ and 
$0.1533^{\circ} \mathrm{C}$, respectively (see TABLE II)) compared with the linearly variable $K_{i}$ PID controller, the proposed hybrid fuzzy-PID can still rapidly respond to the transient and recover the system from the sensor bias failure.

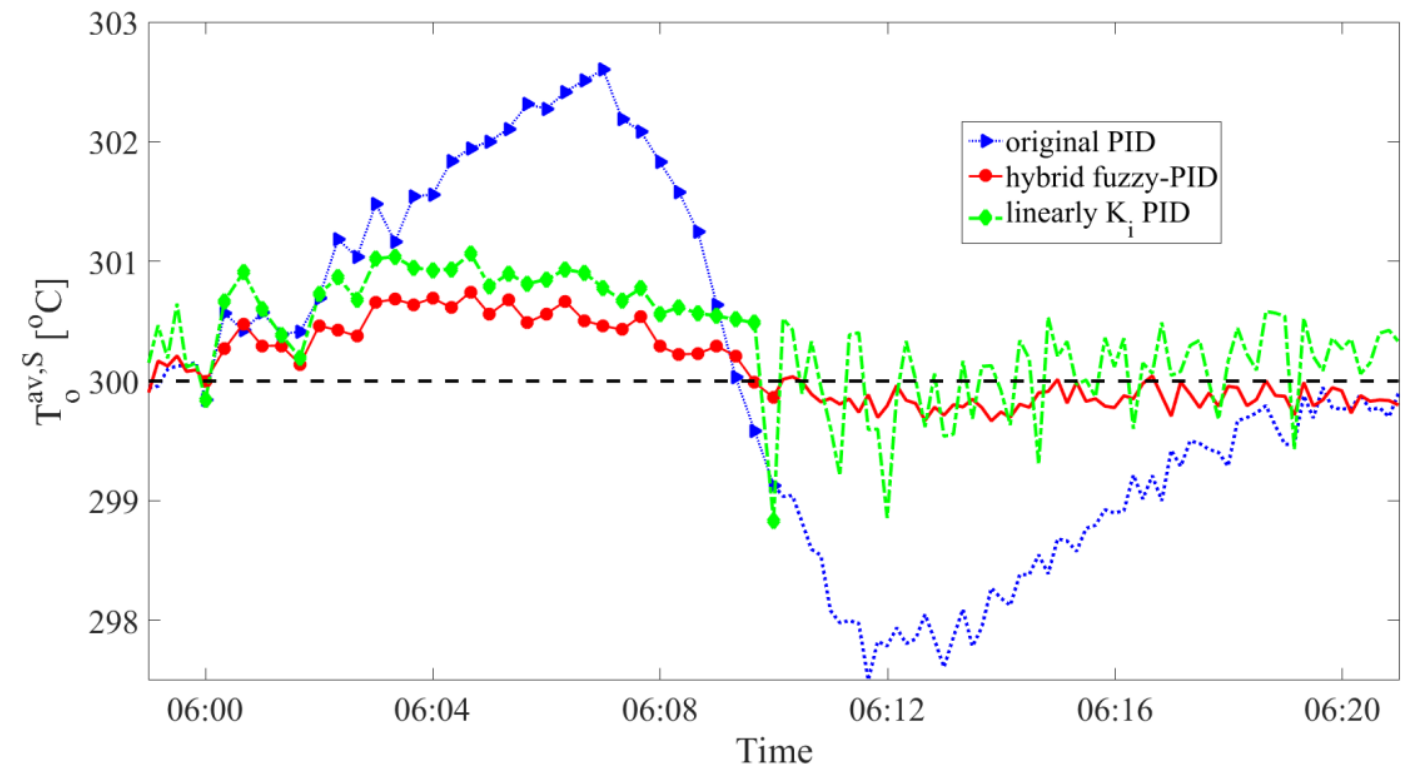

Fig. 22. Comparison of the $T_{o}^{a v, S}$ evolution with the optimized hybrid fuzzy-PID controller (continuous line), with the linear variable $K_{i}$ PID (dashed line) and with the original PID (dotted line), under the sensor drift failure scenario

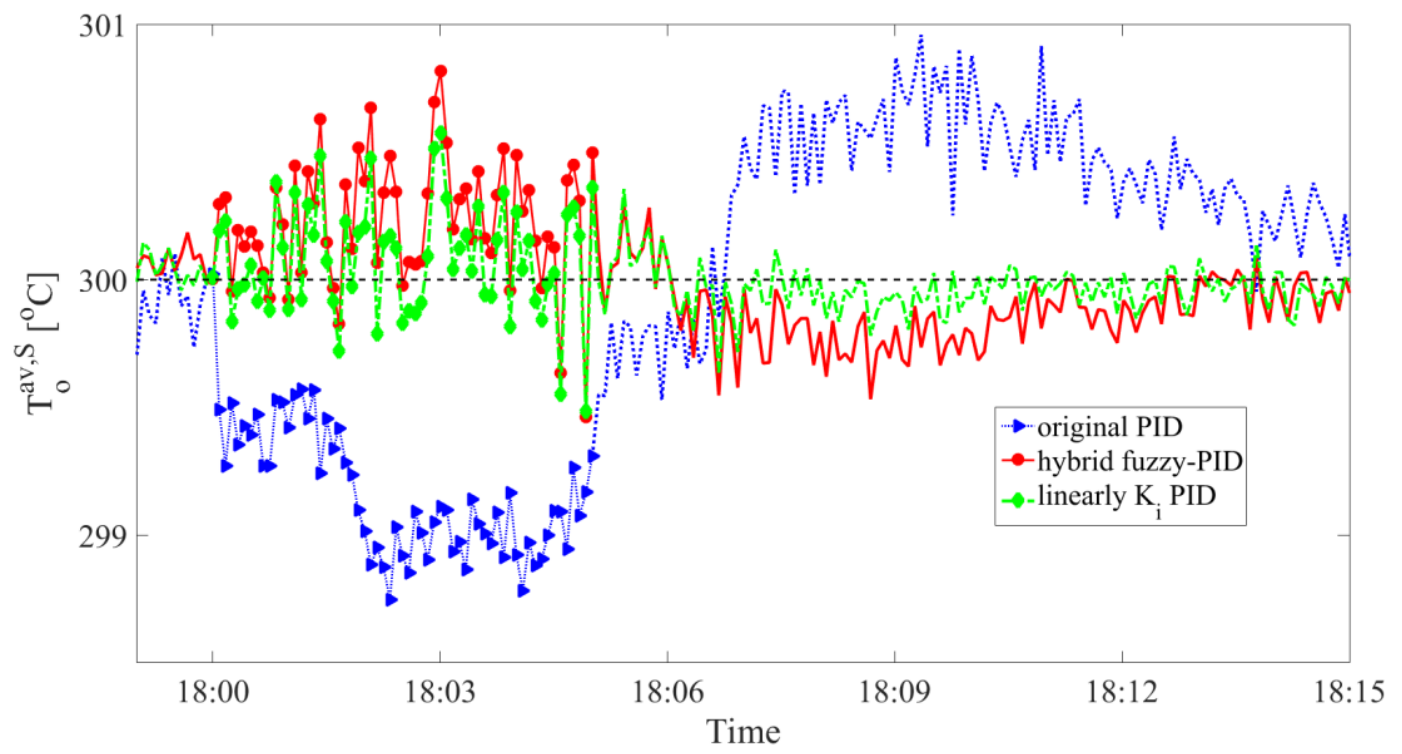

Fig. 23. Comparison of the $T_{o}^{a v, S}$ evolution with the optimized hybrid fuzzy-PID controller (continuous line), with the linear variable $K_{i}$ PID (dashed line) and with the original PID (dotted line), under the sensor bias failure scenario

In conclusion, the proposed hybrid fuzzy-PID controller achieves less average 
drifts $\bar{e}_{S S}$ than other controllers, in realistic scenarios of daily cycles of inlet air temperatures and also in accidental transients due to wrong sensor measurements, in the end preventing the system dynamics from deviating from steady-state beyond safety limits.

\section{CONCLUSIONS}

A hybrid fuzzy-PID control strategy is proposed for controlling a Cyber-Physical System (CPS), under varying environmental conditions. Environmental parameters values are fed to the hybrid fuzzy-PID, which adaptively optimizes the PID gains for controlling the physical variables of interest so as to keep them within preset safety bounds and, thus, improve the real-time performance of CPSs. To increase the transparency of the fuzzy reasoning underpinning the control, a grid-type fuzzy partitioning approach is proposed for optimizing the fuzzy sets and fuzzy rules, which are learnt from examples of input-output data pairs.

For illustration purposes, the proposed controller is applied for the control of the LBE-XADS secondary side average temperature, by adaptively responding to changes of the inlet air temperature. Results demonstrate the benefits that the hybrid fuzzy-PID controller offers over traditional PIDs, effectively reducing the resettling time of the system response to changes in the inlet air temperature.

\section{APPENDIX. SENSITIVITY ANALYSIS FOR THE IDENTIFICATION OF THE OPTIMAL NUMBER OF FUZZY SETS}

In this analysis, a number $S=3,5,7,9,11$ of input membership functions $T$ are tested, resulting in $S$ output fuzzy sets, according to the procedure of Section III.B.b. The 18 samples of Section IV.A are run with the LBE-XADS model equipped with the resulting hybrid fuzzy-PID controllers. Results are shown in Fig. A.1: Fig. A.1(a) shows that the hybrid fuzzy-PIDs with $S=7$ and $S=11$ perform better than the others, because $A_{S P}$ is below 300 (at any environmental temperature), whereas the others cannot. Fig. A.1(b) shows that $S=7$ is to be preferred, because $\bar{e}_{S S}$ is smaller than $0.07^{\circ} \mathrm{C}$ and 
acceptable (when $T_{a, C}^{i n, S}$ larger than $8^{\circ} \mathrm{C}$ ).

The compromise between performance, robustness and computational demand has, thus, led us to set up a hybrid fuzzy-PIDs with 7 sets of membership functions.

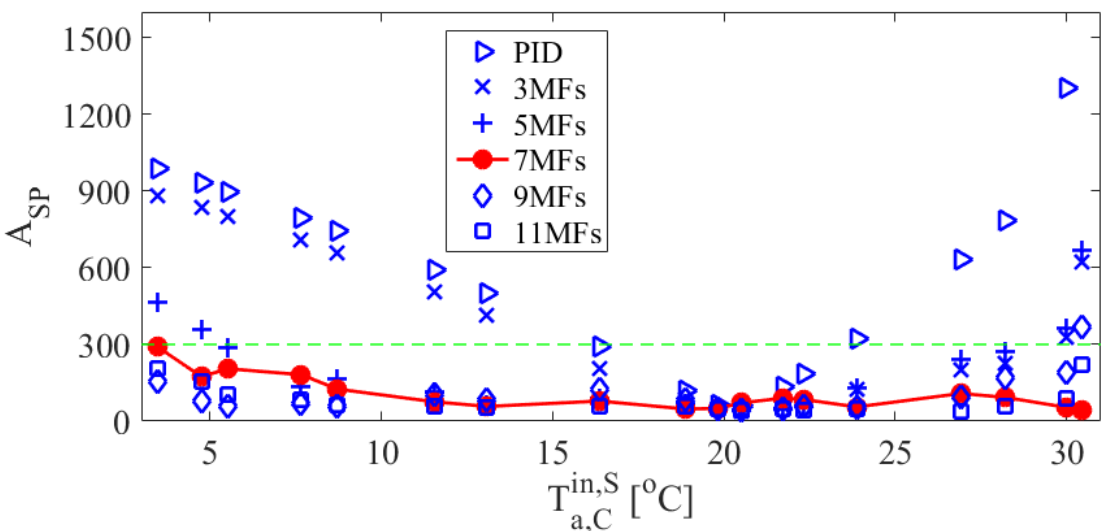

(a)

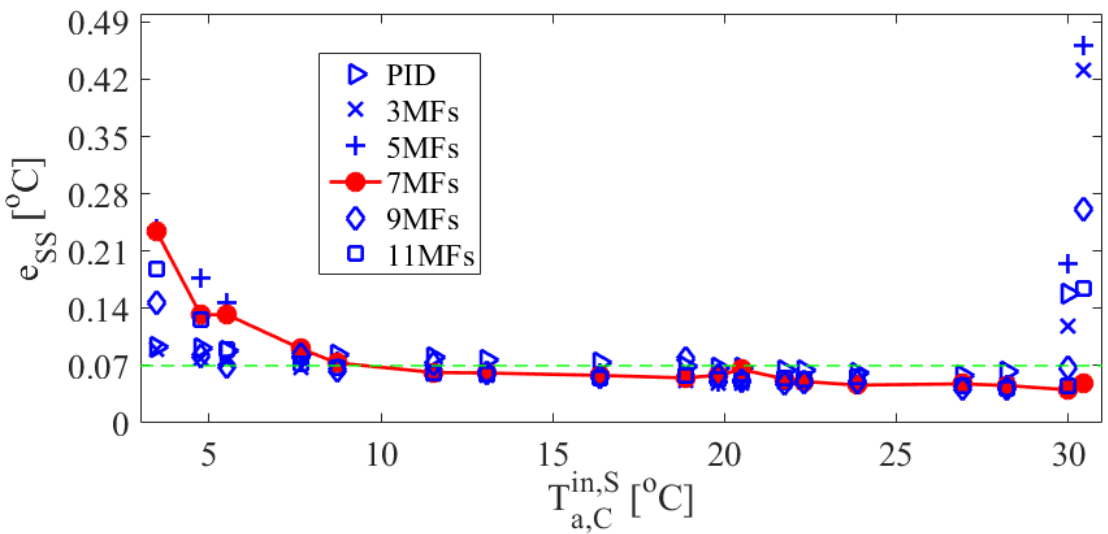

(b)

Fig. A.1. SA results of the samples obtained from the hybrid fuzzy-PID controller with different sets of membership functions and from the original PID: (a) settling area $A_{S P}$; (b) steady-state drift $\bar{e}_{S S}$

\section{REFERENCES}

[1] Khaitan, S. K., \& McCalley, J. D. (2015). Design techniques and applications of cyberphysical systems: A survey. IEEE Systems Journal, 9(2), 350-365.

[2] Lee, E. A. (2008, May). Cyber physical systems: Design challenges. In 2008 11th IEEE International Symposium on Object and Component-Oriented Real-Time Distributed Computing (ISORC) (pp. 363-369). IEEE.

[3] Wang, S., Wang, D., Su, L., Kaplan, L., \& Abdelzaher, T. F. (2014, December). Towards cyberphysical systems in social spaces: The data reliability challenge. In Real-Time Systems Symposium (RTSS), 2014 IEEE (pp. 74-85). IEEE.

[4] Kim, K. D., \& Kumar, P. R. (2012). Cyber-physical systems: A perspective at the centennial. Proceedings of the IEEE, 100(Special Centennial Issue), 1287-1308. 
[5] Bradley, J. M., \& Atkins, E. M. (2015). Optimization and control of cyber-physical vehicle systems. Sensors, 15(9), 23020-23049.

[6] Macana, C. A., Quijano, N., \& Mojica-Nava, E. (2011, October). A survey on cyber physical energy systems and their applications on smart grids. In Innovative Smart Grid Technologies (ISGT Latin America), 2011 IEEE PES Conference on (pp. 1-7). IEEE.

[7] Kaur, K., \& JayPrakash, L. T. (2014, September). Modeling and simulation of Cyber Physical Systems: A case of an adaptive water management system. In Confluence the Next Generation Information Technology Summit (Confluence), 2014 5th International Conference- (pp. 267-273). IEEE.

[8] Wei, C. \& Söffker, D. (2016). Optimization strategy for PID-controller design of AMB rotor systems. IEEE Transactions on Control Systems Technology, 24(3), pp.788-803.

[9] Ang, K. H., Chong, G., \& Li, Y. (2005). PID control system analysis, design, and technology. IEEE transactions on Control Systems Technology, 13(4), 559-576.

[10] Karer, G., \& Škrjanc, I. (2016). Interval-model-based global optimization framework for robust stability and performance of PID controllers. Applied Soft Computing, 40, 526-543.

[11] Lee, K., Lee, K. H., Lee, J. I., Jeong, Y. H., \& Lee, P. S. (2013). A new design concept for offshore nuclear power plants with enhanced safety features. Nuclear Engineering and Design, 254, 129-141.

[12] Shein, W. W., Cheng, Z., Tan, Y., \& Lim, A. O. (2013, August). Study of temperature control using cyber-physical system approach in home environment. In Cyber-Physical Systems, Networks, and Applications (CPSNA), 2013 IEEE 1st International Conference on (pp. 78-83). IEEE.

[13] Radhakrishnan, N., Su, Y., Su, R., \& Poolla, K. (2016). Token based scheduling for energy management in building HVAC systems. Applied Energy, 173, 67-79.

[14] Hu, B. G., Mann, G. K., \& Gosine, R. G. (2001). A systematic study of fuzzy PID controllersfunction-based evaluation approach. IEEE transactions on fuzzy systems, 9(5), 699-712.

[15] Brown, C. and Gabbar, H.A. (2014). Fuzzy logic control for improved pressurizer systems in nuclear power plants. Annals of Nuclear Energy, 72, pp.461-466.

[16] Lamba, R., Singla, S.K. and Sondhi, S., 2017. Fractional order PID controller for power control in perturbed pressurized heavy water reactor. Nuclear Engineering and Design, 323, pp.84-94.

[17] Marseguerra, M., \& Zio, E. (2003). Model-free fuzzy tracking control of a nuclear reactor. Annals of Nuclear Energy, 30(9), 953-981.

[18] Lianzhong, L., \& Zaheeruddin, M. (2007). Hybrid fuzzy logic control strategies for hot water district heating systems. Building Services Engineering Research and Technology, 28(1), 35-53.

[19] Duan, X. G., Deng, H., \& Li, H. X. (2013). A saturation-based tuning method for fuzzy PID controller. IEEE Transactions on Industrial Electronics, 60(11), 5177-5185.

[20] Li, X., Song, Y. J., \& Han, S. B. (2008). Frequency control in micro-grid power system combined with electrolyzer system and fuzzy PI controller. Journal of Power Sources, 180(1), 468-475.

[21] Kumbasar, T. (2014). A simple design method for interval type-2 fuzzy PID controllers. Soft Computing, 18(7), 1293-1304.

[22] Civelek, Z., Lüy, M., Çam, E., \& Barışç1, N. (2016). Control of Pitch Angle of Wind Turbine by Fuzzy Pid Controller. Intelligent Automation \& Soft Computing, 22(3), 463-471.

[23] Zhao, Y., Du, X., Xia, G. and Gao, F., 2015. A novel coordinated control for Integrated Pressurized Water Reactor. Annals of Nuclear Energy, 85, pp.1029-1034.

[24] Castellano, G., Fanelli, A. M., \& Mencar, C. (2003, October). A fuzzy clustering approach for mining diagnostic rules. In Systems, Man and Cybernetics, 2003. IEEE International Conference 
on (Vol. 2, pp. 2007-2012). IEEE.

[25] Meza, J. L., Santibáñez, V., Soto, R., \& Llama, M. A. (2012). Fuzzy self-tuning PID semiglobal regulator for robot manipulators. IEEE Transactions on Industrial Electronics, 59(6), 2709-2717.

[26] Hu, Y. C. (2007). Simple fuzzy grid partition for mining multiple-level fuzzy sequential patterns. Cybernetics and Systems: An International Journal, 38(2), 203-228.

[27] Lin, C. T., Lin, C. J., \& Lee, C. G. (1995). Fuzzy adaptive learning control network with on-line neural learning. Fuzzy Sets and Systems, 71(1), 25-45.

[28] Hussain, S., Gabbar, H. A., Bondarenko, D., Musharavati, F., \& Pokharel, S. (2014). Comfort-based fuzzy control optimization for energy conservation in HVAC systems. Control Engineering Practice, $32,172-182$.

[29] D’Andrea, E., \& Lazzerini, B. (2013). A hierarchical approach to multi-class fuzzy classifiers. Expert Systems with Applications, 40(9), 3828-3840.

[30] Cammi, A., Luzzi, L., Porta, A. A., \& Ricotti, M. E. (2006). Modelling and control strategy of the Italian LBE-XADS. Progress in Nuclear Energy, 48(6), 578-589.

[31] Zio, E., \& Di Maio, F. (2009). Processing dynamic scenarios from a reliability analysis of a nuclear power plant digital instrumentation and control system. Annals of Nuclear Energy, 36(9), 13861399.

[32] Wang, L. X., \& Mendel, J. M. (1992). Generating fuzzy rules by learning from examples. IEEE Transactions on systems, man, and cybernetics, 22(6), 1414-1427.

[33] Zadeh, L. A. (1965). Fuzzy sets. Information and control, 8(3), 338-353.

[34] Klir, G., \& Yuan, B. (1995). Fuzzy sets and fuzzy logic (Vol. 4). New Jersey: Prentice hall.

[35] Zio, E., Baraldi, P., Librizzi, M., Podofillini, L., \& Dang, V. N. (2009). A fuzzy set-based approach for modeling dependence among human errors. Fuzzy Sets and Systems, 160(13), 1947-1964.

[36] Chen, M., Sun, X., Christensen, R. N., Shi, S., Skavdahl, I., Utgikar, V., \& Sabharwall, P. (2016). Experimental and numerical study of a printed circuit heat exchanger. Annals of Nuclear Energy, 97, 221-231.

[37] Alur, R., 2015. Principles of cyber-physical systems. MIT Press.

[38] Qin, G., Liu, M., Zou, J. \& Xin, X. (2015). Vector control algorithm for electric vehicle AC induction motor based on improved variable gain PID controller. Mathematical Problems in Engineering, vol. 2015, Article ID 875843, 9 pages, 2015. doi:10.1155/2015/875843.

[39] Er, M. J., \& Sun, Y. L. (2001). Hybrid fuzzy proportional-integral plus conventional derivative control of linear and nonlinear systems. IEEE Transactions on Industrial Electronics, 48(6), 1109 1117.

[40] Shein, W. W., Tan, Y., \& Lim, A. O. (2012). PID controller for temperature control with multiple actuators in cyber-physical home system. International Conference on Network-Based Information Systems, 8, (pp. 423-428). IEEE Computer Society.

[41] Wang, L. X. (1993). Stable adaptive fuzzy control of nonlinear systems. IEEE Transactions on fuzzy systems, 1(2), 146-155.

[42] Rakhtala, S. M., \& Roudbari, E. S. (2016). Fuzzy PID control of a stand-alone system based on PEM fuel cell. International Journal of Electrical Power \& Energy Systems, 78, 576-590.

[43] Aliotta, S., Barucca, L., Casamirra, M., Castiglia, F., Giardina, M., Mansani, L. and Monti, R., 2002 , October. Loss of flow assessment in a LBE-cooled XADS concept. In Seventh Information Exchange Meeting on Actinide and Fission Product Partitioning and Transmutation. Jeju (Vol. 14, p. 16). 
[44] Tao, J., Sun, Q., Sun, H., Chen, Z., Dehmer, M. and Sun, M., 2017. Dynamic Modeling and Trajectory Tracking Control of Parafoil System in Wind Environments. IEEE/ASME Transactions on Mechatronics, 22(6), pp.2736-2745.

[45] Tiganasu, A., Lazar, C. and Caruntu, C.F., 2017, May. Cyber Physical Systems-Oriented Design of Cooperative Control for Vehicle Platooning. In Control Systems and Computer Science (CSCS), 201721 st International Conference on (pp. 465-470). IEEE.

[46] Xu, L., Lu, J. and Zhang, J., 2017, May. Speed Control of Pure Electric Vehicle Based on Adaptive Fuzzy PID Controller. In International Symposium for Intelligent Transportation and Smart City (pp. 20-26). Springer, Singapore.

[47] Carvajal, J., Chen, G. and Ogmen, H., 2000. Fuzzy PID controller: Design, performance evaluation, and stability analysis. Information sciences, 123(3), pp.249-270. 